ANSP-M-1

DECEMBER 1971

Copy No. 60

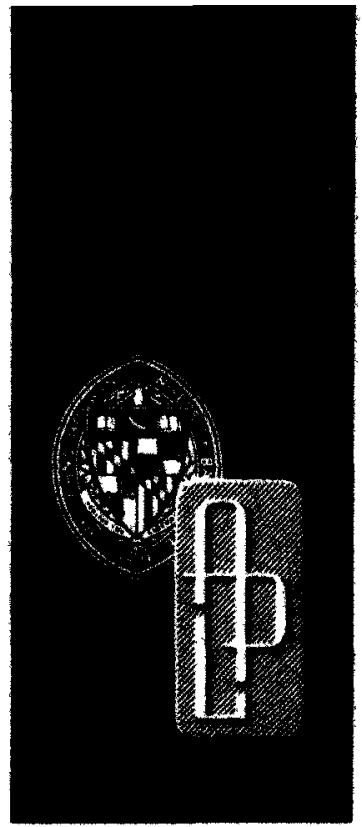

Aerospace Nuclear Safety Program

\title{
REVIEW OF \\ GRAPHITE ABLATION THEORY AND EXPERIMENTAL DATA
}

by L. L. PERINI

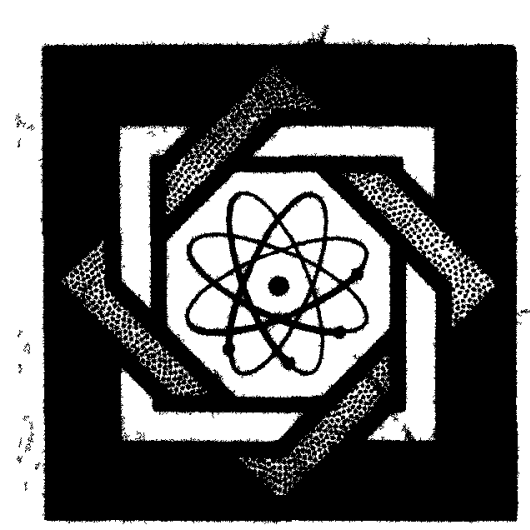

THE JOHNS HOPKINS UNIVERSITY APPLIED PHYSICS LABORATORY MASTER 


\section{DISCLAIMER}

This report was prepared as an account of work sponsored by an agency of the United States Government. Neither the United States Government nor any agency Thereof, nor any of their employees, makes any warranty, express or implied, or assumes any legal liability or responsibility for the accuracy, completeness, or usefulness of any information, apparatus, product, or process disclosed, or represents that its use would not infringe privately owned rights. Reference herein to any specific commercial product, process, or service by trade name, trademark, manufacturer, or otherwise does not necessarily constitute or imply its endorsement, recommendation, or favoring by the United States Government or any agency thereof. The views and opinions of authors expressed herein do not necessarily state or reflect those of the United States Government or any agency thereof. 


\section{DISCLAIMER}

Portions of this document may be illegible in electronic image products. Images are produced from the best available original document. 
ANSP-M-1
DECEMBER 1971

Aerospace Nuclear Safety Program

REVIEW OF

GRAPHITE ABLATION THEORY AND EXPERIMENTAL DATA

by L. L. PERINI
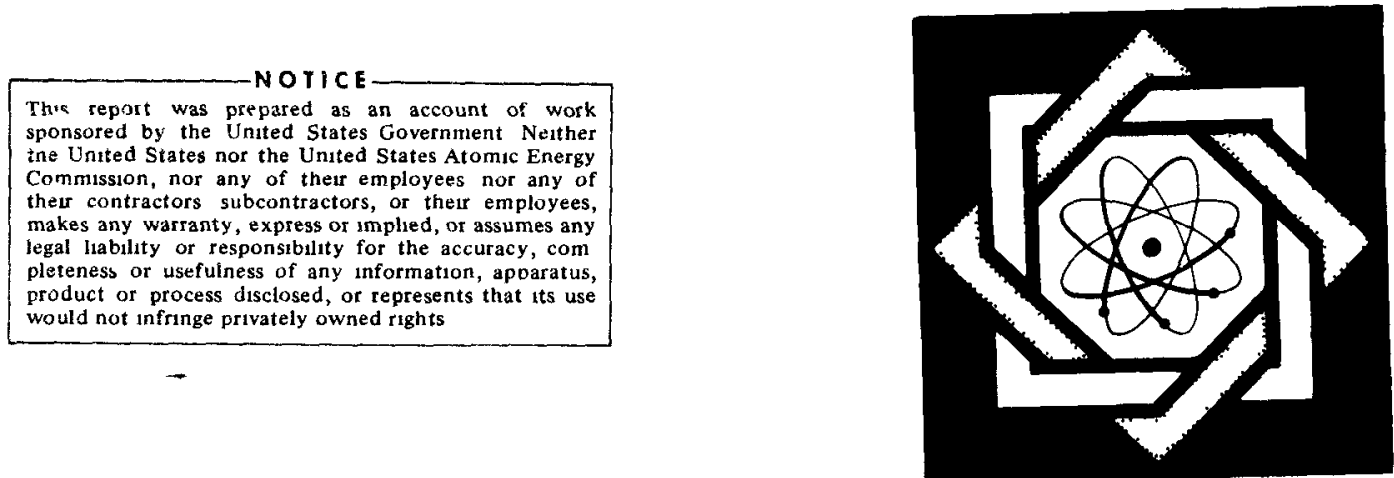

THE JOHNS HOPKINS UNIVERSITY - APPLIED PHYSICS LABORATORY 8621 Georgia Avenue, Silver Spring, Maryland 20910 


\section{FOREWORD}

The work reported herein was conducted by the Applied Physics

Laboratory Aeronautics Division for the Atomic Energy Commission Safety

Branch, Space Nuclear Systems Office. Activities of the Aeronautics

Division are under the general supervision of $\mathrm{Dr}$. William H. Avery. The

Project Engineer for the Aerospace Nuclear Safety Program is James C. Hagan. 


\section{ABSTRACT}

This memorandum reviews theoretical graphite ablation models and supporting experimental data with the purpose of determining the degree of confidence to be placed in predictions of graphite ablation from the methods currently in use. From this review of theory and data available to date, it is recommended, for the present, that graphite mass loss predictions for the Pioneer $F$ fuel capsule reentries be based on "moderate" oxidation rates (following Metzger, et a1.), Scala's co diffusion limit, and a thermochemical model for the high temperature sublimation regime based on JANAF(69) species data along with an empirical correlation for erosion losses. 
The assumptions employed in developing the graphite ablation loss mode1, currently being used in the Aerospace Nuclear Safety Thermal analysis program, are reviewed and the requisite empirical information (rate parameters, thermochemical species, and diffusion limit mass transfer parameter) is discussed.

The experimental data are grouped into two classes: laboratory tests and engineering tests. Laboratory test data (furnace) for the oxidation rate of pyrolytic graphite (PG) from six sources are compared, and the rate parameters are developed from the data. The resulting rates predict oxidation losses considerably less than ATJ graphite; however, test data from engineering tests (arc jets) do not substantiate the lowe rates for PG. A number of reasons for this anomaly can be postulated (mechanical erosion, measurement techniques), but there is insufficient information to resolve the discrepancy. Engineering test data for ATJ graphite from five sources covering a wide temperature range ( 800 to $4000^{\circ} \mathrm{K}$ ) are compared to the theoretical model. In the transition region between reaction-rate controlled and diffusion-limited oxidation rates, the "moderate" rates developed by Metzger, et al., represent the bulk of the data, and in the diffusion-limited region there is a scatter in the data amounting to a $+10 \%$ to $-50 \%$ variation about the theoretical predictions. Sublimation predictions based on the JANAF(69) thermodynamic data result in underestimates of experimental mass losses reaching a peak value of $-70 \%$ at the data extreme of $\mathrm{p}=4 \mathrm{~atm}$ and $\mathrm{T}=4000^{\circ} \mathrm{K}$. A correlation, as suggested by Lundell and 
THE NOHNS MOPXINS UNIVERSITY APPLIED PHYSICS LABORATORY SILVER SPMnNe. MARYLAND

Dickey, is developed for the difference which is attributed to mechanical erosion losses. However, there is insufficient information to decide what percentages of the differences are due to mechanical erosion and/or the neglect of higher-order carbon species.

In view of the scatter in the data a conservative model, for graphite ablation, is currently recommended consisting of the "moderate" rate, coupled with Scala's Co diffusion limited value for the oxidation regime and the JANAF(69) thermochemica1 data along with the correlation developed for mechanical erosion effects for the sublimation regime. Variations about this base case should be performed for the critical trajectories.

Experimental data for POCO graphite (currently favored heat shield material) is lacking and modifications to the theoretical model will be performed when the oxidation characteristics of POCO are determined. 
THE JOHNS MOPKINS UNIVEASITY APPLIED PHYSICS LABORATORY

SILVER SPRING. MATYLAND

TABLE OF CONTENTS

I. INTRODU CTION

II. REVIEW OF PERTINENT ABIATION THEORY

A. Reaction Rate Controlled Regime

B. Transition Regime

C. Diffusion Limit

D. Sublimation Regime

E. Summary

III. EXPERIMENTAL DATA FOR GRAPHITE ABLATION
A. Laboratory Tests
B. Engineering Tests
C. Summary

IV. COMPARISON OF THEORY AND EXPERIMENT

REFERENCES

NOMENCLATURE 
Fig. 1 Aerothermodynamic Environment for a Superorbita1 and an Orbita 1 Decay Trajectory. $\beta=28 \mathrm{lb} / \mathrm{ft}^{2}$ at $\mathrm{z}=400 \mathrm{~K} \mathrm{ft}$, $\mathrm{R}_{\mathrm{N}}=0.5 \mathrm{ft}$.

Fig. 2 Comparison of Transition Region Mass Loss Solutions, $R_{N}=0.5$ inches 。

Fig. 3 Comparison of Sublimation Mass Loss Solutions $-P=1$ atm.

Fig. 4 Experimental Oxidation Rates for Pyrolytic Graphite.

Fig. 5 Pyrolytic Graphite Transition Region Mass Loss Rates.

Fig。 6 Experimental Ablation Rates. Golovina and Khaustovich, ${ }^{32}$ and Welsch and Chung. 13

Fig。 7 Experimental Ablation Rates. Metzger, Engel and Dioconis。 11

Fig. 8 Experimental Ablation Rates. Miller and Sutton. 36

Fig. 9 Experimental Ablation Rates. Maahs. 37

Fig. 10 Experimental Sublimation Rates. Lundell and Dickey. ${ }^{24}$ JANAF curves for $\mathrm{p}=1 \mathrm{~atm}$.

Fig. 11 Incremental Mass Loss Rate $\left(\dot{\mathrm{m}}_{i}\right)$ above JANAF(69) Rates.

Fig. 12 Comparison of Maahs ${ }^{37}$ and Miller and Sutton ${ }^{36}$ Test Data.

Fig. 13 Comparison of Theoretical Models and Experimenta1 Data for Axisymmetric Bodies. 


\section{INTRODUCTION}

The Applied Physics Laboratory is aiding the Atomic Energy Commission in the evaluation of safety aspects of spacecraft employing nuclear power sources, including predictions of the probability of maintaining an intact fuel source in the event of an abort. These predictions require the analysis of aerothermodynamic behavior for a variety of reentry configurations on a variety of possible trajectories. Since safety is the primary concern, reentry configurations and trajectories are selected, based on mission abort probabilities, that yield the severest conditions of possible failure modes leading to breaching of the fuel source container; $i_{0} e .$, thermal stress, ablation and impact. For the current Pioneer F mission, for example, the superorbital and orbital decay trajectories have been utilized for thermal studies. ${ }^{1}$ To illustrate the variety of gas dynamic phenomena encountered, Fig. 1 shows altitude-velocity profiles of the trajectories for a reentry configuration with a ballistic coefficient (at $400 \mathrm{~K} \mathrm{ft}$ ) of $28 \mathrm{lb} /$ $\mathrm{ft}^{2}$. Superimposed on the figure are various curves indicating the stagnation pressure and temperature levels encountered, the chemistry of the flow and the gas dynamic regimes encountered which must be considered in a thorough reentry analysis. In the studies, knowledge of the heating rate distributions and ablation losses are fundamental.

This memorandum is restricted to reviewing theoretical models for graphite ablation and supporting experimental data. The results presented herein evolved from a review of the open literature in an attempt to determine the degree of confidence to be associated with the methods currently in use in estimating the ablation of a graphite material. Similar reviews of 
other aspects of reentry aerothermodynamic analyses will be conducted in the future.

A comprehensive analysis, covering the oxidation and sublimation loss of a carbon materia1, was developed by Scala and coworkers at General Electric in $1958-1963^{2}$ and has formed the basis and standard of comparison for subsequent models. The generally accepted physical description of the processes is as follows. As a body reenters the atmosphere, its surface temperature rises. When the temperature reaches a certain leve 1 , which depends on the surface material's reactivity, a heterogeneous chemical reaction (oxidation) between the hot boundary layer and the surface material ensues. In this first 'reaction-rate"controlled' regime, the surface oxidation rate increases exponentially with surface temperature (e.g。, by an Arrhenius kinetic mechanism). Reaction-rate control persists with increasing surface temperature until the diffusional transport of oxidant to the surface becomes too slow to maintain the exponential increase in reaction rate. This 'transition regime' extends to the temperature level where the surface reaction becomes completely diffusion controlled. At this condition, the reaction is said to be in the diffusion-limited regime and is characterized by surface oxidation occurring in stoichiometric proportions (the stoichiometry depending on the products formed). As the surface temperature continues to increase, the oxidation rate remains diffusionlimited until a critical temperature/pressure condition is reached at which the graphitic material also begins to sublime. In this sublimation regime the mass loss rate again increases exponentially with surface temperature as dictated by the partial pressure of the vaporizing carbon species. 
Section II presents a qualitative description of the above model, Section III discusses the available experimental data, and Section IV presents a comparison of the theoretical model and the experimental data.

\section{REVIEW OF PERTINENT ABLATION THEORY}

The numerical solutions upon which current graphite ablation models are based have been generated from the basic conservation equations of continuity, species, momentum and energy subject to laminar, steady-state boundary layer assumptions. These equations are:*

\section{Globa1 Continuity}

$$
\frac{\partial(\rho \mathrm{ur})}{\partial x}+\frac{\partial\left(\rho v r^{\bar{k}}\right)}{\partial y}=0
$$

Species Conservation

$$
\rho u \frac{\partial C_{i}}{\partial x}+\rho v \frac{\partial C_{i}}{\partial y}=\frac{\partial}{\partial y}\left(D_{i} \rho \frac{\partial C_{i}}{\partial y}\right)+w_{i}
$$

Energy

$$
\rho u \frac{\partial h}{\partial x}+\rho v \frac{\partial h}{\partial y}=\frac{\partial}{\partial y}\left(k \frac{\partial T}{\partial y}\right)+u \frac{\partial p}{\partial x}+\mu\left(\frac{\partial u}{\partial y}\right)^{2}+\frac{\partial}{\partial y}\left[\Sigma_{i} D_{i} \rho h_{i} \frac{\partial C_{i}}{\partial y}\right]
$$

Momentum

$$
\begin{array}{ll}
\begin{array}{ll}
\mathrm{x}-\mathrm{direction} \\
\text { (tangentia })
\end{array} & \rho u \frac{\partial u}{\partial x}+\rho_{v} \frac{\partial u}{\partial y}=-\frac{\partial P}{\partial x}+\frac{\partial}{\partial y}\left(\mu \frac{\partial u}{\partial y}\right) \\
y-\text { direction (norma } 1) & \frac{\partial P}{\partial y}=0
\end{array}
$$

\footnotetext{
* See p. 39 for a nomenclature list.
} 


$$
\begin{aligned}
& \overline{\mathrm{k}}_{\mathrm{o}}=0 \text { for planar flow and } 1 \text { for axisymmetric flow } \\
& \mathrm{P}_{\mathrm{r}}=\overline{\bar{C}}_{\mathrm{p}} \mu / \mathrm{k}=\text { Prandt number } \\
& \mathrm{L}_{\mathrm{e}}=\rho \overline{\mathrm{C}}_{\mathrm{p}_{i}} / \mathrm{k}=\text { Lewis number } \\
& \overline{\mathrm{C}}_{\mathrm{p}}=\sum_{i} \mathrm{C}_{i} \mathrm{C}_{\mathrm{p}_{i}} \\
& \mathrm{~h}=\sum_{i} \mathrm{~h}_{i}=\sum_{i} \int_{298}^{\mathrm{T}} \mathrm{C}_{\mathrm{p}_{i}} \mathrm{dt}+\underset{i}{\sum} \mathrm{h}_{i} 298
\end{aligned}
$$

This set of equations has been employed in previous studies of heat transfer $^{3}$ and ablation ${ }^{4}$ for axisymmetric bodies. The equations are reduced to a set of ordinary differential equations by assuming flow similarity (i.e., the profiles across the boundary layer are a function of a single variable). The applicability of similarity to the thermochemical equilibrium solution in general has been discussed by Lees. ${ }^{5}$ For the axisymmetric stagnation point the similarity assumption is valid. ${ }^{5}$ The formulation of the boundary condition as well as flow chemistry depends on the problem under study. Normally equilibrium and/or frozen thermochemistry assumptions are employed so as to bracket the effects of kinetics. Scala, ${ }^{4}$ in his studies of the diffusion-limited region, assumed both equilibrium and frozen chemistry and computed boundary layer transport properties $\left(k, \mu\right.$ and $D_{i}$ ) based on statistical mechanics considerations by employing the rigid sphere model and the Leonard-Jones 6-12 potential function. Scala concluded that the mass loss rates were independent of the chemistry assumption employed, i.e., frozen or equilibrium. Fay and Riddell, ${ }^{3}$ in a study of the heat transfer at the stagnation point of a blunt axisymmetric body, also assumed both frozen and equilibrium flow and concluded that surface heat transfer is independent of 
the chemistry as long as the surface is catalytic. This conclusion was also arrived at by Lees. 5 In these numerical studies ionization effects were not considered, and diffusion effects due to pressure and temperature gradients were neglected. In terms of the elemental mass fraction, $\alpha_{j}$, the species conservation equation transforms to

$$
\left.\rho u \frac{\partial \alpha_{j}}{\partial x}+\rho v \frac{\partial \alpha_{j}}{\partial y}=\frac{\partial}{\partial y} \mid D_{12} \rho \frac{\partial \alpha_{j}}{\partial y}\right)
$$

It has been assumed in deriving Eq. (7) that the diffusion coefficients $\mathrm{D}_{i}$ can be replaced by a binary diffusion coefficient $\mathrm{D}_{12}$. As shown by Lees, 6 this assumption is consistent with Ficks law and considers the gas to be composed of two typical species; for air a typical atom and molecule, i.e., all atomic species have approximately the same molecular weight and the same collision cross section as do al1 the molecular species. ${ }^{*}$ The energy equation, by employing the binary diffusion assumption, can now be written:

$$
\begin{aligned}
\rho u \frac{\partial h_{t}}{\partial x} & +\rho v \frac{\partial h_{t}}{\partial y}=\frac{\partial}{\partial y}\left(\frac{\mu}{P_{r}} \frac{\partial h_{t}}{\partial y}\right)+\frac{\partial}{\partial y}\left[\mu\left(1-\frac{1}{P_{r}}\right) \frac{\partial\left(u^{2} / 2\right)}{\partial y}\right] \\
& +\frac{\partial}{\partial y}\left[D_{12} \rho\left(1-\frac{1}{L_{e}}\right) \sum_{i} \frac{\partial C_{i}}{\partial y}\right]
\end{aligned}
$$

where $h_{t}=h+u^{2} / 2$ is the total stream enthalpy. Equations (7) and (8) are the basic equations from which the simplified solution is

\footnotetext{
${ }^{*}$ Knuth ${ }^{7}$ in a note takes issue on the conceptual model of Ficks Law and indicates the approximation is on ly good when describing the diffusion of each of these two groups of species, not the individual species.
} 
derived. The assumption $L_{e}=P_{r}=1$ reduces Eqs. (7) and (8) to the same form, i.e.,

$$
\begin{aligned}
& \text { pu } \left.\frac{\partial \alpha_{j}}{\partial x}+\rho v \frac{\partial \alpha_{j}}{\partial y}=\frac{\partial}{\partial y} \mid \mu \frac{\partial \alpha_{j}}{\partial y}\right) \\
& \left.\rho u \frac{\partial h_{t}}{\partial x}+\rho v \frac{\partial h_{t}}{\partial y}=\frac{\partial}{\partial y} \mid \mu \frac{\partial h_{t}}{\partial y}\right)
\end{aligned}
$$

and indicates that the total enthalpy and elemental species concentration gradients across the boundary layer possess local similarity. By assuming a linear gradient across the boundary layer, then

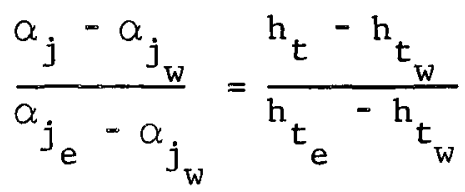

The $\alpha_{j}$ are the elementa 1 mass fractions. They are related to the species mass fractions via

$$
a_{j}=\sum_{i} a_{j i} c_{i} m_{j} / m_{i}
$$

where $a_{j i}$ is the number of $j$ atoms in the $i$ th species. In general, the net mass flux at the surface, ( $\rho v)$, is equal to the sum of the convective ( $\rho v \alpha_{j}$ ) and diffusion $\left(\rho V_{j} \alpha_{j}\right)$ fluxes, $i . e .$,

$$
(\rho v)_{w}=\left(\rho v \alpha_{j}\right)_{w}+\left(\rho V_{j} \alpha_{j w}\right.
$$

For a binary mixture, Fick's law states that

$$
\rho V_{j} \alpha_{j}=-\rho D_{12}\left(\partial \alpha_{j} / \partial y\right)
$$




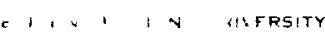

ELF, LAT FATORY

D ven a no mazyaAmo

Therefore,

$$
(\rho v)_{w}=\left(\rho \vee \alpha_{j}\right)_{w}-\left(\rho D_{12} \frac{\partial \alpha_{j}}{\partial y}\right)_{w}
$$

The standard definition for the Stanton number $C_{h}$ is

$$
\rho_{e} U_{e} C_{h}=\frac{\dot{q}}{h_{t_{e}}-h_{t_{w}}}=\frac{k\left(\partial h_{t} / \partial y\right)_{w}}{\bar{C}_{p}\left(h_{t_{e}}-h_{t_{w}}\right)}=\frac{\rho D_{12}\left(\partial h_{t} / \partial y\right)_{w}}{\left(h_{t_{e}}-h_{t_{w}}\right)}
$$

and the definition for the blowing rate $\mathrm{B}^{\prime}$ (also called the dimensionless driving force, 'mass transfer parameter') is

$$
B^{\prime} \equiv(\rho v)_{w} / \rho_{e} u_{e} C_{h}
$$

For a non-surface element, the net $f l_{u x}(\rho v)_{w}=0$, so that, from Eqs. and $(11-13)$,

$$
\alpha_{j w}=\alpha_{j} /\left(1+B^{\prime}\right)
$$

For a surface element, the concentration at the boundary layer edge $\alpha_{j}=0$, and, at the surface,

$$
\alpha_{j_{w}}=B^{\prime} /\left(1+B^{\prime}\right)
$$

As an example, consider a $\mathrm{C}-\mathrm{N}-\mathrm{O}$ system applicable to the carbon-air reaction. For this case, carbon is the surface material and the elemental concentrations at the surface are

$$
\alpha_{O_{w}}=\alpha_{0} /\left(1+B^{\prime}\right), \alpha_{N_{w}}=\alpha_{N_{e}} /\left(1+B^{\prime}\right), \text { and } \alpha_{C_{w}}=B^{\prime} /\left(1+B^{\prime}\right)
$$


From these concentration equations,

$$
\alpha_{C_{w}} /\left(\alpha_{0}+\alpha_{N}\right)_{w}=B^{\prime}
$$

which states that $B^{\prime}$ can be interpreted as the surface's local 'fuel-air' weight ratio. For an air model composed of $21 \% \mathrm{O}_{2}$ and $79 \% \mathrm{~N}_{2}$ by volume, then $\alpha_{0}=0.23$ and $\alpha_{N_{e}}=0.77$. Equations (12), (13), and (16), along with relations describing the surface reaction and chemistry assumptions, represent the basic equations utilized in forming a simple graphite ablation model for the unity Lewis number case. The remainder of this review is restricted to this unity Lewis number model. Free stream flow conditions and body geometry enter in the evaluation of $\mathrm{C}_{\mathrm{h}}$ which combined with the governing surface chemistry, dictate the value of $B^{\prime}$.

The evaluation of conditions for the four thermochemical regimes of graphite, i。e, reaction rate controlled, transition, diffusion control and sublimation, as based on this simplified model, is discussed below.

\section{A. Reaction-Rate Controlled Regime}

Experimental surface reaction rate data is normally presented in the Arrhenius plane, $i_{\circ} e ., \log \dot{m}$ vs $1 / T$, in an attempt to correlate the data with the empirical Arrhenius rate equation,

$$
\stackrel{\circ}{\mathrm{m}}=\mathrm{P}_{O_{w}}^{\mathrm{n}} \mathrm{k}_{0} \mathrm{e}^{-\mathrm{E} / \mathrm{RT}} \mathrm{w}_{\mathrm{w}}
$$

where $\stackrel{m}{m}$ is the carbon mass loss rate, $k_{0}$ is the 'frequency factor' or 'reaction rate constant', $\mathrm{n}$ is the order of the reaction, $\mathrm{E}$ is the activation energy, and $\mathrm{P}_{\mathrm{O}_{\mathrm{w}}}$ is the partial pressure of the oxidant at the surface. 
It is acknowledged that $\mathrm{Eq} \cdot(18)$ is a gross simplification of the graphite surface reaction rate, and other more complex forms have been advocated 8 attempting to account for other influences such as adsorption of reactants and desorption of products. Values of $k_{0}, n$, and $E$ reported by various experimentalists show a great degree of disparity, attesting somewhat to the inapplicability of $\mathrm{Eq}$. (18) for a heterogeneous carbon reaction. However, judging from published arc-jet experimental data on ATJ graphite (discussed in Section IIIB) and the state of knowledge existing in understanding the fundamental kinetic processes occurring in the carbon-air surface reaction, it appears that $\mathrm{Eq} .(18)$ is as valid as any of the other methods. (The conclusion in a comprehensive review of the subject, ${ }^{10}$ published in 1959, appears to be still valid: "At present, however, there is no clear understanding of why a given carbon reacts at a particular rate with a given gas under a fixed set of operating conditions".) Scala, 4 in an attempt to bracket the available data, utilized a set of 'slow' and 'fast' values for $\mathrm{E}$ and $\mathrm{k}_{0}$ with $\mathrm{n}=$ 1/2. Subsequently Metzger, et $a 1^{11}$ based on experimental arc-jet data, formulated a third set that resulted in rates between the 'fast' and 'slow' values of Scala and labeled herein as the 'moderate' rates. (The resulting values of $E$ and $k_{0}$ are reproduced in Fig. 2.)

\section{B . Transition Regime}

Defining

$$
\stackrel{\circ}{\mathrm{m}}_{\mathrm{R}} \equiv\left(\mathrm{PX}_{0}\right)^{\mathrm{n}} \mathrm{k}_{0} e^{-\mathrm{E} / \mathrm{RT}} \mathrm{w}_{\mathrm{w}}
$$

\footnotetext{
"Some authorities ${ }^{9}$ believe that differing experimental techniques are also
} influencing the reported differences. 
where the mole fraction $\mathrm{X}_{\mathrm{O}}=\mathrm{P}_{\mathrm{O}_{e}} / \mathrm{P}$, Eq. (18) can be written as

$$
\stackrel{\mathrm{m}}{=} \stackrel{\circ}{\mathrm{m}}_{\mathrm{R}}\left(\alpha_{\mathrm{O}_{\mathrm{w}}} / \alpha_{\mathrm{O}}\right)^{\mathrm{n}}
$$

It is assumed that $\mathrm{P}_{\mathrm{O}_{\mathrm{w}}} / \mathrm{P}_{\mathrm{O}} \approx \alpha_{\mathrm{O}} / \alpha_{\mathrm{w}} \mathrm{O}_{\mathrm{e}}$. The assumption is not seriously in error since the values of $\mathrm{B}^{\prime}$ in the transition region are $\operatorname{smal1}\left(0<\mathrm{B}^{\circ}<\right.$ 0.175 ) for carbon. The mass flux of oxygen arriving at the wall is given by combining Eqs. (11), (9), and (12) to give

$$
\stackrel{\circ}{\mathrm{m}}_{0}=\rho_{e} \mathrm{u}_{\mathrm{e}} \mathrm{c}_{\mathrm{h}}\left(\alpha_{0}-\alpha_{\mathrm{o}}\right)
$$

At this point, the conversion from $\stackrel{\circ}{m}_{0}$ to $\stackrel{\circ}{m}$ must be made requiring an assumption to be made on the stoichiometry. If one assumes that co is the carbon product then

$$
\mathrm{C}+\frac{1}{2} \mathrm{O}_{2}+1.88 \mathrm{~N}_{2} \rightarrow \mathrm{CO}+1.88 \mathrm{~N}_{2} \text { and } \dot{\mathrm{m}}=\frac{3}{4} \dot{\mathrm{m}}_{\mathrm{O}} \text {. }
$$

Assuming, however, that $\mathrm{CO}_{2}$ is the carbon product, then

$$
\mathrm{C}+\mathrm{O}_{2}+3.26 \mathrm{~N}_{2} \rightarrow \mathrm{CO}_{2}+1.88 \mathrm{~N}_{2} \text { and } \stackrel{\mathrm{m}}{=}=\frac{3}{8} \dot{\mathrm{m}}_{0}
$$

The question of what determines the primary product, $\mathrm{CO}$ or $\mathrm{CO}_{2}$, has as yet not been established. It appears that $\mathrm{CO}$ and $\mathrm{CO}_{2}$ are both primary products with the ratio $\mathrm{CO} / \mathrm{CO}_{2}$ increasing sharply with temperature, so that above $\sim$ $1300^{\circ} \mathrm{K}$, the primary product becomes $\mathrm{Co}^{9}$ solely. This is essentially in agreement with equilibrium calculations of the $\mathrm{C}+\mathrm{CO}_{2} \rightarrow 2 \mathrm{Co}$ reaction presented in Ref。10, wherein for $P=1$ atm and $T=1300^{\circ} \mathrm{K}, \mathrm{CO} / \mathrm{CO}_{2} \cong 200$ 
whereas at $\mathrm{T}=1000^{\circ} \mathrm{K}, \mathrm{Co} / \mathrm{CO}_{2} \cong 2$. Based on these considerations, we have assumed that $\mathrm{CO}$ is the primary product, so that

$$
\dot{\mathrm{m}}=\rho_{\mathrm{e}} \mathrm{u}_{\mathrm{e}} \mathrm{c}_{\mathrm{h}}\left(\frac{3}{4} \alpha_{0_{\mathrm{e}}}\right)\left(1-\frac{\alpha_{0}}{\alpha_{0}}\right) .
$$

If we define

$$
\stackrel{\circ}{\mathrm{m}}_{\mathrm{D}}=\rho_{\mathrm{e}} \mathrm{u}_{\mathrm{e}} \mathrm{C}_{\mathrm{h}} \frac{3}{4} \alpha_{\mathrm{e}}
$$

then

$$
\stackrel{\circ}{\mathrm{m}}=\stackrel{\circ}{\mathrm{m}}_{\mathrm{D}} \cdot\left[1-\left(\alpha_{\mathrm{o}_{\mathrm{w}}} / \alpha_{0}\right)\right]
$$

when comparing Eqs. (22) and (13), it is found that, in the diffusionlimited regime with $\mathrm{CO}$ as the primary product, $\mathrm{B}_{\mathrm{D}}^{\prime}=\frac{3}{4} \alpha_{0} \cdot$ For air, with $\alpha_{O_{e}}=0.23, B_{D}^{\prime}=0.1725$. The two rates given by Eqs. (23) and (20) must be equal. Assuming a first-order reaction $(n=1)$, we obtain, for the transition regime,

$$
\dot{\mathrm{m}} / \dot{\mathrm{m}}_{\mathrm{D}}=\left[1+\left(\dot{\mathrm{m}}_{\mathrm{D}} / \dot{\mathrm{m}}_{\mathrm{R}}\right)\right]^{-1}
$$

whereas for a $1 / 2$-order reaction $(n=1 / 2)$,

$$
\dot{\mathrm{m}} / \dot{\mathrm{m}}_{\mathrm{D}} \simeq\left\{\frac{1}{2}+\left[\frac{1}{4}+\left(\dot{\mathrm{m}}_{\mathrm{D}} / \dot{\mathrm{m}}_{\mathrm{R}}\right)^{2}\right]^{\frac{1}{2}}\right\}^{-1}
$$

Equation (24) represents the so-called 'resistance in series' formula, as developed by Frank-Kamenetskii, ${ }^{12}$ and utilized by Scala in an early paper 4 for a 1/2-order reaction. In later papers, ${ }^{2}$ the expression 


$$
\stackrel{\mathrm{m}}{\stackrel{\mathrm{m}}{\mathrm{D}}_{\mathrm{D}}}=\left[1+\left(\stackrel{\circ}{\mathrm{D}}_{\mathrm{m}} / \stackrel{\circ}{\mathrm{R}}^{2}\right)^{2}\right.
$$

was used and is a close approximation to Eq. (25). Another method for the transition region was advocated by Welsh and Chung $^{13}$ and consists basically of utilizing equilibrium considerations to determine the constant in Eq. (22) as a function of temperature and pressure. This results in the 'double plateau' theory where the first plateau corresponds to a $\mathrm{CO}_{2}$ diffusion limit and the second plateau to the co limit.

\section{Diffusion Limit}

The correlation equation arrived at by $\mathrm{Scala}^{2}$ from numerical solutions of the basic boundary layer equations in the diffusion limited regime is

$$
\dot{\mathrm{m}}_{\mathrm{D}}=0.00635^{*}\left(\mathrm{P}_{\mathrm{S}} / \mathrm{R}_{\mathrm{N}}\right)^{\frac{1}{2}} 1 \mathrm{~b} / \mathrm{sec}-\mathrm{ft} \mathrm{t}^{2}
$$

where the stagnation pressure $P_{S}$ is in atm, and the nose radius $R_{N}$ is in feet. Scala found that the differences between frozen and equilibrium assumptions was small and that the increase in heat transfer due to chemical reaction in the boundary layer was approximately offset by the reduction in heat transfer due to mass transfer addition to the boundary layer via surface ablation (i.e., blowing). Utilizing this latter finding and by assuming $\mathrm{CO}$ to be the primary product, then, from Eq. (22),

$$
\stackrel{\circ}{\mathrm{D}}^{2}=0.1725 \rho_{e} \mathrm{u}_{\mathrm{e}} \mathrm{C}_{\mathrm{h}}
$$

\footnotetext{
* The original report ${ }^{4}$ listed the constant as 0.0062 , however, a more recent report ${ }^{2}$ lists the value as 0.00635 .
} 
where $\mathrm{C}_{\mathrm{h}_{\mathrm{o}}}$ is the non-blowing Stanton number. By employing the basic form of Fay and Riddel1's $s^{3}$ correlation equations for a cold wall at conditions of $L_{e}=1, P_{r}=0.70$ and $\rho_{s} \mu_{s}=\rho_{e} \mu_{e}$, then

$$
{ }^{o} e^{u} c_{h_{o}}=\dot{q}_{c_{w}} / h_{t}=0.94\left[\rho_{s} \mu_{s}\left(\left.\frac{d u}{d x}\right|_{s}\right]^{\frac{1}{2}}\right.
$$

when considering standard hypersonic flow assumptions $\left[i . e .,(\mathrm{du} / \mathrm{dx})_{\mathrm{s}}=\right.$ $\sqrt{(\gamma-1) / \gamma} u_{o} / R_{N}$ and $\left.C_{p_{s}} T_{s}=u_{o}^{2} / 2\right]$, the equation of state, $\rho_{s}=p_{s} /\left(R_{g} T_{s}\right)$, the Sutherland viscosity relation for $\mathrm{T}_{\mathrm{S}} \gg 200^{\circ} \mathrm{R}, \mu_{\mathrm{S}}=\mathrm{C}_{1} \mathrm{~T}_{\mathrm{S}}^{\frac{1}{2}}$ where $\mathrm{T}_{\mathrm{s}}$ is in ${ }^{\circ} \mathrm{R}$, and $\mathrm{C}_{1}=0.725 \times 10^{-6} \mathrm{Ib} / \mathrm{ft}-\mathrm{sec}-\mathrm{R}^{\frac{1}{2}}$, and finally the perfect gas relation, $C_{P}=\frac{\gamma}{\gamma-1} R_{g}$ the following expression is obtained:

$$
\rho_{e} u_{e} C_{h_{0}}=0.94\left[C_{1} \frac{P_{s}}{R_{N}} \sqrt{\frac{2 g}{R_{g}}}\right]^{\frac{1}{2}}
$$

Using this latter relation in Eq. (28), with $R_{g}=53.3 \mathrm{ft}-1 \mathrm{~b} / 1 \mathrm{~b}-{ }^{\circ} \mathrm{R}$ and $\mathrm{g}=32.2 \mathrm{ft} / \mathrm{sec}^{2}$, gives

$$
\stackrel{\circ}{\mathrm{m}}_{\mathrm{D}}=0.00666\left(\mathrm{P}_{\mathrm{s}} / \mathrm{R}_{\mathrm{N}}\right)^{\frac{1}{2}} 1 \mathrm{~b} / \mathrm{sec}-\mathrm{ft} \mathrm{t}^{2}
$$

The close agreement of Eq. (29) with Eq. (27) (within 5\%) is fortuitous; however, it does show the general form of Eq. (27) to be theoretically valid。

Oxidation-rate profiles based on Eq. (19) for $\dot{\mathrm{m}}_{\mathrm{R}}$, Eq. (27) for $\dot{\mathrm{m}}_{\mathrm{D}}$, and $\mathrm{Eq}$. (25) for $\dot{\mathrm{m}}_{\mathrm{m}}^{\mathrm{m}}$ are illustrated in Fig. 2. The reaction rate constants $k_{o}$ and $\mathrm{E}$ for the 'fast', 'slow' and 'moderate' Arrhenius models utilized in these calculations are shown in Fig, 2. Since $\dot{\mathrm{m}}_{\mathrm{R}}$ and $\dot{\mathrm{m}}_{\mathrm{D}}$ are both proportional to $\sqrt{\mathrm{P}_{\mathrm{S}}}$, the resulting $\dot{\mathrm{m}} / \dot{\mathrm{m}}_{\mathrm{D}}$ ratio is independent of pressure. 
Also shown for comparison is the 'moderate' rate profile using Eq. (26). As noted, the mass loss ratio computed with Eq. (25), yields slightly lower mass ratios. A nose radius $\mathrm{R}_{\mathrm{N}}$ of $1 / 2^{\prime \prime}$ was used in the calculations. Increases in $R_{N}$ would lead to increases in $\dot{\mathrm{m}} / \dot{\mathrm{m}}_{\mathrm{D}}$. The rate profile curve labeled 'very slow' will be discussed in Section III.

\section{Sublimation Regime}

In the sublimation region, graphite mass loss becomes primarily dependent upon the partial pressure of the carbon vapor species at the surface. Scala also developed the following mass loss correlation * for graphite sublimation based on numerical solutions of the boundary layer equations for a nine species $\left(0, \mathrm{O}_{2}, \mathrm{~N}, \mathrm{~N}_{2}, \mathrm{CO}, \mathrm{CO}_{2}, \mathrm{C}, \mathrm{C}_{3}\right.$ and $\left.\mathrm{CN}\right)$ equilibrium mode 1:

$$
\dot{\mathrm{m}} / \dot{\mathrm{m}}_{\mathrm{D}}=1+16 \times 10^{6} \mathrm{p}_{\mathrm{s}}^{-2 / 3} \mathrm{e}^{-1.11 \times 10^{5} / \mathrm{T}_{\mathrm{w}}}
$$

where $\mathrm{P}_{\mathrm{S}}$ is in atm, and $\mathrm{T}_{\mathrm{w}}$ is in ${ }^{\circ} \mathrm{R}$. In Fig. 3, Eq. (30), for $\mathrm{P}_{\mathrm{S}}=1$ atm, is shown as the 'SCALA' curve. Scala also concluded that the mass flux rate could be "approximated closely in a very simple manner, i.e., by the solution of a set of algebraic thermochemical equations which yields the elemental carbon composition at the wa11."14 This procedure is followed in the computer programs developed by the Aerotherm Corporation, ${ }^{15}$ which are used at APL in evaluating one-dimensional ablatiòn characteristics..

\footnotetext{
*Equation (30) is obtained by combining Eqs. (33) and (37) from Ref. 14.
} 
THE JOHNS HOPKINS UNIVERSITY

APPLIED PHYSICS LABORATORY

SILVER SPRING MARYLAND

In terms of the mass transfer parameter, $\mathrm{B}^{\prime}$, the elemental carbon mass fraction is given by the last of Eqs. (17), i.e.,

$$
\alpha_{c_{w}}=B^{\prime} /\left(1+B^{\prime}\right)
$$

It remains to relate $\mathrm{B}^{\prime}$ to surface temperature and pressure. The mass loss ratio is given by

$$
\dot{\mathrm{m}} / \dot{m}_{\mathrm{D}}=\frac{\mathrm{B}^{\prime}}{\mathrm{B}_{\mathrm{D}}^{\prime}} \frac{\left(\mathrm{C}_{\mathrm{h}} / \mathrm{C}_{\mathrm{h}_{0}}\right)}{\left(\mathrm{C}_{\mathrm{h}} / \mathrm{C}_{h_{\mathrm{O}}}\right)}
$$

where $\mathrm{C}_{\mathrm{h}_{0}}$ is the non-blowing Stanton number. Various correlations are currently in use relating $\mathrm{C}_{\mathrm{h}} / \mathrm{C}_{\mathrm{h}}$ to $\mathrm{B}^{\prime}$. The classic Mickley-Spalding ${ }^{16}$ blowing relation is assumed to apply, i.e.,

$$
\mathrm{C}_{\mathrm{h}} / \mathrm{C}_{\mathrm{h}_{\mathrm{o}}}=\left[\ln \left(1+\mathrm{B}^{\prime}\right)\right] / \mathrm{B}^{\prime}
$$

Combining Eqs. (31) and (32) gives

$$
\dot{\mathrm{m}} / \dot{\mathrm{m}}_{\mathrm{D}}=\ln \left(1+\mathrm{B}^{\prime}\right) / \ln \left(1+\mathrm{B}_{\mathrm{D}}^{\prime}\right)
$$

In an equilibrium, homogeneous thermochemical solution, the independent parameters are basically pressure and temperature. The sublimation process involves a heterogeneous surface reaction involving the equilibrium state, dictated by the vapor pressure of the sublimating species, between the solid and gaseous phases. This additional constraint, in accordance

\footnotetext{
* The selection of a more appropriate correlation should be a subject for further study. Other correlations have been proposed ${ }^{17}$ that attempt to account for a non-air gas.
} 
with Gibbs' phase rule, reduces the number of degrees of freedom by one, so that, for example one need specify only the pressure.

To illustrate the procedure, let us consider the carbon-air system. At the high temperatures under consideration, and for the sake of simplicity, we assume that all of the oxygen has combined to form $\mathrm{CO}$, that $\mathrm{C}_{3}$ is the dominant carbon species, and that $\mathrm{N}_{2}$ has not dissociated. For this '3-component' $\left(\mathrm{CO}, \mathrm{C}_{3}, \mathrm{~N}_{2}\right)$ model the gaseous reactions are:

$$
\mathrm{C}+\mathrm{O} \rightarrow \mathrm{CO} \text {, and } \mathrm{C}_{3}+30 \rightarrow 3 \mathrm{CO}
$$

and $\mathrm{N}_{2}$ is treated as an inert component. The surface condition is represented by

$$
\mathrm{C}(\mathrm{S}) \rightarrow \mathrm{C}_{3}
$$

Elemental conservation, in conjunction with Eqs. (16) give

$$
\begin{aligned}
& \alpha_{O_{w}}=\frac{m_{0}}{\mathrm{Pm}} \mathrm{P}_{\mathrm{CO}}=\frac{\alpha_{0}}{1+\mathrm{B}}, \\
& \alpha_{N_{W}}=2 \frac{m_{\mathrm{N}}}{\mathrm{P}} \mathrm{P}_{\mathrm{N}_{2}}=\frac{\alpha_{\mathrm{N}_{\mathrm{e}}}}{1+\mathrm{B}}, \text { and } \\
& \alpha_{\mathrm{C}_{W}}=\frac{m_{\mathrm{C}}}{\mathrm{Pm}}\left(\mathrm{P}_{\mathrm{CO}}+3 \mathrm{P}_{\mathrm{C}_{3}}\right)=\frac{\mathrm{B}^{\prime}}{1+\mathrm{B}}, .
\end{aligned}
$$

The mixture molecular weight is given by

$$
m=\left(\mathrm{P}_{\mathrm{CO}} \mathrm{m}_{\mathrm{CO}}+\mathrm{P}_{\mathrm{N}_{2}} \mathrm{~m}_{2}+\mathrm{P}_{\mathrm{C}_{3}} \mathrm{~m}_{\mathrm{C}_{3}}\right) / \mathrm{P} \text {. }
$$


Dalton's law of partial pressure is

$$
\mathrm{P}=\mathrm{P}_{\mathrm{CO}}+\mathrm{P}_{\mathrm{N}_{2}}+\mathrm{P}_{\mathrm{C}_{3}}
$$

and the surface reaction equilibrium is represented as

$$
\mathrm{K}_{\mathrm{C}_{3}}=\mathrm{P}_{\mathrm{C}_{3}}
$$

where $\mathrm{K}_{\mathrm{P}_{\mathrm{C}_{3}}}$ is the equilibrium constant (i.e., the partial pressure) between $\mathrm{C}_{3}$ and $\mathrm{C}(\mathrm{s})$. Solving for $\mathrm{P}_{\mathrm{C}_{3}} / \mathrm{P}$ from Eqs. (35-37) gives

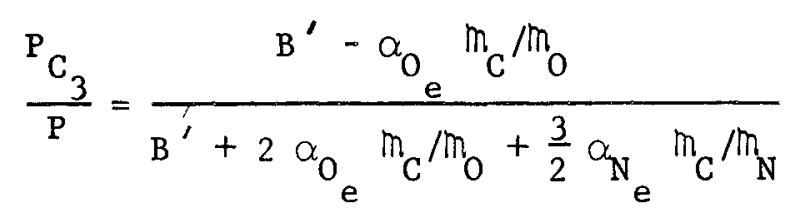

Using $\mathrm{B}_{\mathrm{D}}^{\prime}=\alpha_{\mathrm{O}} m_{\mathrm{C}} / m_{\mathrm{O}}$ and noting that $\frac{3}{2} \alpha_{\mathrm{N}} m_{\mathrm{C}} / m_{\mathrm{N}} \approx 1$, we have

$$
\frac{\mathrm{P}_{C_{3}}}{\mathrm{P}}=\frac{\mathrm{B}^{\prime}-\mathrm{B}_{\mathrm{D}}^{\prime}}{\mathrm{B}^{\prime}+2 \mathrm{~B}_{\mathrm{D}}^{\prime}+1}
$$

From thermochemical tabulations ${ }^{18}$ of $\mathrm{K}_{\mathrm{P}_{\mathrm{C}_{3}}}$ we have

$$
\log _{10} \mathrm{P}_{\mathrm{C}_{3}}=9.64-39800 \mathrm{~T}^{-1}
$$

where $\mathrm{T}$ is in ${ }^{\circ} \mathrm{K}$. The procedure is to select a $\mathrm{B}^{\prime}$ (elemental composition) and stagnation pressure $P=P_{S}$, solve for the surface temperature $\left(T=T_{w}\right)$ from Eqs. (39) and (40) and $\dot{\mathrm{m}} / \dot{\mathrm{m}}_{\mathrm{D}}$ from Eq. (34). The results (labeled 'simple $C_{3} \operatorname{mode} 1^{\prime}$ ) are shown in Fig. 3 for $P_{S}=1$ atm. Also shown for 
comparison, are the results of a 14-species model (labeled 'JANAF (69) ') with carbon species including $C_{1}$ through $C_{5}$ as derived from a thermochemical equilibrium computer program ${ }^{19}$ using current ('1969') JANAF thermochemical data. As noted, the simple $\mathrm{C}_{3}$ model tends to underestimate the mass loss ratios for a given temperature; however, the trends are similar. The differ ences between the 'JANAF (69)' and 'SCALA' results are due to differences in the thermochemical data and in the methods of solution. It should be remarked that the comparisons between the 'JANAF (69)' and 'SCALA' curves could be altered by selection of a different blowing relationship. At a given surface temperature, increasing the pressure results in lower mass loss ratios.

Sublimation loss rates for graphite have been computed, utilizing the procedure outline above and assuming the existence of higher order carbon species. Dolton, et $a 1 ., 20$ in an attempt to investigate sublimation kinetics, considered $\mathrm{C}_{1}$ to $\mathrm{C}_{16}$ and generated the requisite thermodynamic data for the postulated higher-order species based on the method of Pitzer and Clementi (a method which utilizes measured data for $\mathrm{C}_{3}$ ). At approximately the same time, Kratsch et a 1.21 published sublimated mass loss rates assuming $\mathrm{C}_{1}$ to $\mathrm{C}_{30}$ carbon species. The thermodynamic data for the carbon species were generated by "theoretical methods substantially different from those used by Pitzer and Clementi." The Dolton and Kratsch studies both state that the resulting thermodynamic data yielded good agreement with measurements of the triple-point temperature measurements of graphite. Rindall and Powars, ${ }^{22}$ in a review of the sublimation region, concluded on the basis of Dolton 's 
results that "the calculations for the kinetic case may be approximated by assuming thermochemical equilibrium and simply ignoring high molecular weight carbon vapor species from consideration in the calculations." Data for the Dolton species $\mathrm{C}_{3}$ to $\mathrm{C}_{16}$ have been obtained from the Aerochem Corporation. ${ }^{23}$ The data, as received (curve fits), are referenced to a $0^{\circ} \mathrm{K}$ base and limited in genera 1 to $\mathrm{T}>900^{\circ} \mathrm{K}$. In view of the uncertainty in the data (Ref. 21 indicates a $\pm 20 \%$ uncertainty in the free energy function) the curve fits were converted to the JANAF $298^{\circ} \mathrm{K}$ base by subtracting $5 \%$ of the enthalpy at $3000^{\circ} \mathrm{K}$. The remaining species $\mathrm{C}, \mathrm{C}_{2}, \mathrm{NO}, \mathrm{N}, \mathrm{N}_{2}, \mathrm{CO}, 0,0_{2}$, $\mathrm{CO}_{2}, \mathrm{CN}, \mathrm{C}_{2} \mathrm{~N}_{2}, \mathrm{C}_{4} \mathrm{~N}_{2}$ and $\mathrm{C}(\mathrm{S})$ were obtained from the JANAF data. Based on these species, a thermochemical equilibrium computer program ${ }^{19}$ was utilized to generate the $B^{\prime}-T_{w}$ relationship, and the mass loss ratio was determined via Eq. (34). The results for $\mathrm{P}_{\mathrm{S}}=1$ atm are labeled 'DoLTON' in Fig. 3 and indicate a much higher mass loss rate for a given temperature than either the 'JANAF (69)' or 'SCALA' curves. In light of the conclusion by Rindal1 and Powars, as discussed above, the 'DOLTON' curve can be viewed as the equilibrium limit and the 'JANAF (69)' curve as the kinetic limit. Recent experimental measurements by Lunde11 and Dicky, ${ }^{24}$ to be discussed in Section III, lend support to the 'JANAF (69)' model, i.e., the sublimation process is kinetically controlled and the higher order carbon species do not have time to form.

E. Summary

The model for graphite ablation predictions that has been reviewed in this section is relatively simple to apply and can be adapted to other 
THE JOHNS HOPKINS UNIVERSITY

APPLIED PHYSICS LABORATORY

SILVER SPRING MARYLAND

materials. The basic inputs are the rate parameters $E$ and $k_{o}$ for the ratecontrolled regime, the Stanton number $C_{h}$ and stoichiometry for the diffusionlimited regime, and vapor pressure data and a blowing relationship for the sublimation regime. The model distinguishes between different types of carbon only in the rate-controlled regime, through the parameters $E$ and $k_{0}$. The reentry body's geometry enters in the specification of $C_{h}$. From Lee's relationship, ${ }^{5} \mathrm{C}_{\mathrm{h}}$ depends on the dimensionality of the flow by the factor $2^{\bar{k}} / 2$, where $\bar{k}=1$ for axisymmetric flow (e.g., hemispherical and flat-faced cylinders) and $\vec{k}=0$ for planar flow (e.g., infinite length cylinders). The body shape also enters into the determination of the stagnation point velocity gradient. The method is somewhat restricted in that mechanical erosion, turbulence, rarified flow, and radiation are not included; however, these effects are normally accounted for by assuming that the phenomena are uncoupled and therefore additive.

\section{EXPERIMENTAL DATA ON GRAPHITE ABIATION}

The experimental data fall into two categories: 1) laboratory tests of small rods or plates that are heated either electrically or in a furnace to gain fundamental knowledge concerning the surface reaction mechanisms, and 2) engineering tests of somewhat larger specimen ( $\sim$ "in diameter) configured to represent aerodynamic shapes of interest. The latter tests usually are performed in high-enthalpy, arc-heated tunnels to obtain usable data applicable to the design of thermal protective systems. 
THE JOHNS HOPKINS UNIVERSITY APPLIED PHYSICS LABORATORY SILVER SPRING MARYLAND

\section{A. Laboratory Tests}

The majority of tests over the past four decades are of this nature. This morass of information has been reviewed by others.9, 10 About the only general conclusion that can be formulated from it is that the oxidation rate of carbon depends on factors that have not as yet been universally accounted for by experimentalists (e.g., porosity, atomic structure, surface structure, impurity content, etc.). For the artificial graphites, these factors have been shown to strongly influence physical properties (e.g., density, thermal expansion, Young's modulus, etc.) ${ }^{25}$ and also appear to have a bearing on oxidation characteristics.

Figure 4 shows oxidation rate data for pyrolytic graphite (PG) from six papers, ${ }^{26-31}$ plotted on Arrhenius coordinates $\left(\log \stackrel{\mathrm{m}}{\mathrm{vs}} 1 / \mathrm{T}_{\mathrm{W}}\right)$. The conditions for a11 the data (see Table I) are applicable to the oxidation of $P G$ at atmospheric pressure in air; $P G$ is of interest to the reentry safety analysis program as it is utilized as a backup insulation material for the Pioneer $F$ heat source. $P G$ is characterized by its low porosity, high density, (i.e., 99\% theoretical density), and high degree of anisotropy. It is manufactured by chemical vapor deposition (usually methane) on a suitable substrate. The deposition temperature appears to have a pronounced influence on the physical properties. 25 The data scatter in Fig. 4 spans one to two orders of magnitude. Horton, ${ }^{26}$ Nagle and Strickland-Constable 27 and Wa11s and Strickland-Constable ${ }^{28}$ claim the data are true surface reac-

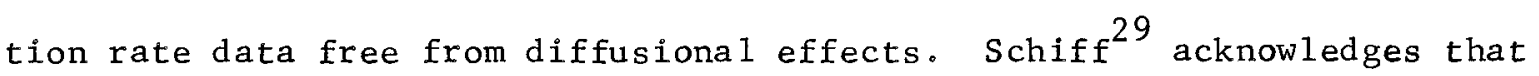
the results are relatively crude and presents the indicated shaded region 
rather than data points. Levy ${ }^{30}$ concluded that above $1144^{\circ} \mathrm{K}$ (represented by the breaks in the four curves in Fig. 4), diffusional effects were influencing the results. The data from Nagle and Walls show a relatively good degree of reproducibility (a factor of 2) and represent two different pyrolytic graphites. In addition, their data tend to agree with the Levy ${ }^{30,31}$ data. The Horton results show relative agreement with the results of Schiff.

Ignoring the apparent peak in the data at $2000^{\circ} \mathrm{K}$, a straight line (dotted in Fig. 4) has been drawn through the preponderance of data. This line gives $k_{0}=13.97 \mathrm{lb}\left(\mathrm{ft}^{3 / 2}-\mathrm{sec}-\mathrm{atm}^{1 / 2}\right)$ and $E=27670 \mathrm{cal} / \mathrm{mole}$. Using Eq. (19) and assuming a half order $(n=1 / 2)$ reaction, the resulting 'rate equation' for $\mathrm{T}_{\mathrm{w}}$ in ${ }^{\circ} \mathrm{K}$ is given as

$$
\stackrel{\circ}{\mathrm{m}}_{\mathrm{R}}=13.97\left(\mathrm{PX}_{\mathrm{O}}\right)^{\frac{1}{2}} \mathrm{e}^{-27670 / \mathrm{RT}_{\mathrm{w}} \mathrm{Ib} /\left(\mathrm{ft}^{2}-\mathrm{sec}\right)}
$$

The rate constant, $\mathrm{k}_{\mathrm{O}}$, and activation energy, $\mathrm{E}$, were evaluated by assuming $\mathrm{X}_{\mathrm{O}_{\mathrm{e}}}=0.21, \mathrm{P}=1 \mathrm{~atm}$ and $\mathrm{R}=1.986 \mathrm{cal} / \mathrm{mole}-{ }^{\circ} \mathrm{K}$.

In comparison, the Metzger correlation for ATJ graphite data obtained in arc jet tests (discussed later) is

$$
\stackrel{\circ}{\mathrm{m}}_{\mathrm{R}}=9.65 \times 10^{5}\left(\mathrm{PX}_{\mathrm{e}}\right)^{\frac{1}{2}} \mathrm{e}^{-44000 / \mathrm{RT}_{\mathrm{w}}} 1 \mathrm{~b} /\left(\mathrm{ft}^{2}-\mathrm{sec}\right)
$$

which indicates oxidation rates for ATJ $\sim 20$ times greater at $\mathrm{T}=1000^{\circ} \mathrm{K}$, and $\sim 300$ times greater at $\mathrm{T}_{\mathrm{w}}=1500^{\circ} \mathrm{K}$, than the corresponding $\mathrm{PG}$ rates. The trends are as expected, since ATJ with its higher porosity would be 
THE JOHNS HOPKINS UNIVERSITY APPLIED PHYSICS LABORATORY

SILVER SPRING. MARYLAND

expected to oxidize more rapidly. In addition, the divergence between the two as surface temperature increases can be rationalized as due to the increase in surface area for the ATJ graphite as the pores enlarge due to oxidation.

In order to illustrate the differences, between ATJ and PG values of $\frac{\circ}{\mathrm{m}} / \stackrel{\mathrm{m}}{\mathrm{D}}$ were computed using Eq. (25) with $\dot{\mathrm{m}}_{\mathrm{D}}$ given by Eq。 (27) and $\stackrel{\circ}{\mathrm{R}}_{\mathrm{R}}$ from Eqs. (41) and (42). The resulting curves are shown in Fig. 5. As noted, the PG oxidation rates are below the diffusion limited value up to the sublimation region $\left(\mathrm{T}_{\mathrm{w}} \sim 3000-3500^{\circ} \mathrm{K}\right)$. Also shown in Fig. 5 are arctunne1 ablation-rate measurements for PG graphite obtained by Maahs 37 in four facilities as discussed later (Section III-B -5). One should be cautious in drawing conclusions on the basis of the data, as other tests by Maahs encompassed three other grades of graphite (including ATJ) and showed no discernable trends as to oxidation rate differences between ATJ and PG (see Fig。9)。

\section{B. Engineering Tests}

The tests in this category are specifically directed toward obtaining ablation loss rates for the purpose of generating design information for aerospace configurations. As with the laboratory type of tests, reproducibility is difficult to attain. In addition, the measurement of surface temperature, heating rates, ablation rates and gas dynamic properties represents a formidable task in the usually severe test environments. Furthermore, the quality and gas dynamic nature (i.e., steadiness and 
THE JOHNS HOPKINS UNIVERSITY APPLIED PHYSICS LABORATORY

SILVER SPRING MARYLAND

uniformity) of the flow emanating from the arcs can be difficult to control. In spite of these obstacles, a fair amount of data has been accumulated throughout the thermochemical temperature range of interest, (i.e., 900$4000^{\circ} \mathrm{K}$ ) for ATJ grade graphite over the past decade. These data are briefly summarized below. The data of Golovina and Khaustovich ${ }^{32}$ are an exception since they represent electrically heated electrode carbon specimens tested in a laboratory environment. However, they are included since it has recently been recommended that these data be considered representative for "other less graphitic carbons" than pyrolytic graphite. ${ }^{8}$

1) Golovina and Khaustovich, Russia, 1962, Ref. 32

The tests were conducted for electrode carbon $(\rho=1.71 \mathrm{~g} / \mathrm{cc})$ spheres, $15 \mathrm{~mm}$ in diameter. The specimens were electrically heated and the air flow rate was maintained at $\sim 2 \mathrm{ft} / \mathrm{sec}$. A spring balance was used to measure weight changes and a photoelectric pyrometer for temperature measurements. No pressure data were reported. The results encompass a temperature range from 1070 to $2772^{\circ} \mathrm{K}$ (37 data points) and the theoretical calculations of diffusional rates (assuming $\mathrm{CO}$ as the primary product) given by the authors were used to form the $\mathrm{m} / \stackrel{\circ}{\mathrm{D}}$ ratio. The results are shown plotted in Fig. 6. In a discussion of these results R.H. Essenhigh ${ }^{33}$ expressed the opinion, based on considerations of the diffusional boundary layer thickness, that the tests were free of diffusional effects, in contrast to Golovina and Khaustovich's conclusion.

2) Welsh and Chung, Aerospace Corp., 1963, Ref. 13

Welsh and Chung, in support of their postulated 'double-plateau' theory, reported ATJ graphite ablation data (17 data points) encompassing 
the temperature range of 890 to $2250^{\circ} \mathrm{K}$. A subsonic air jet heated by an electric plasma was impinged "norma11y on one end of an ATJ-grade graphite cylindrical specimen。" Further details (e。g。, pressure, measurement techniques, etc。) were not reported. The data were presented as the $\mathrm{m} / \stackrel{\circ}{\mathrm{D}}_{\mathrm{D}}$ ratio and used as given. The results are shown plotted in Fig.6。

3) Metzger, Enge1 and Dioconis, Genera1 Electric Co., 1965, Ref. 11

The authors presented a summary of an experimental program on the "graphite degradation in reentry environments." Preliminary data, included in this summary paper, were reported in $1962 .^{34}$ The tests were performed in an arc-heated hypersonic tunnel at the Space Sciences Laboratory of the General Electric Co. Electrode contamination is claimed to be low ( 100 parts per milion). The bulk of the data was obtained for ATJ graphite utilizing flat faced cylindrical specimens of $1 / 16,1 / 4$ and 1 inch diameter. Surface temperatures ranged from 1100 to $2900^{\circ} \mathrm{K}$, and stagnation (body) pres * sures ranged from 0.007 to 0.056 atm. Pressures were measured with a pitot probe, heat transfer with calorimeter models, and surface temperatures with a two-color pyrometer. Mass loss data were obtained by measuring specimen length changes at the stagnation point after exposure to the test stream.

The data, used herein, were modified on two accounts by Metzger, et a1. Due to test facility limitations, the test specimen's local flow conditions ranged from continuum to near free molecular flow. The data obtained at rarefied flow conditions were adjusted to permit comparison to continuum flow theory. The adjustment consisted of "applying a Stanton number ratio correction factor to the data in the diffusion controlled regime or an effective pressure ratio correction factor to data in the reaction rate controlled regime." A second correction was applied to convert the results to an equivalent spherical geometry. 
The resulting data (over 200) are shown in Fig. 7. The values tabulated in Ref. $11^{*}$ were divided by the diffusion limit given by Eq. (27) to form the $\dot{\mathrm{m}} / \dot{\mathrm{m}}_{\mathrm{D}}$ ratio. The low-temperature oxidation data were used by Metzger, et $a 1_{0}$, to arrive at the reaction rate constants, $k_{0}$ and $E$, listed in Fig. 2 as the 'moderate' values.

4) Miller and Sutton, NASA Langley, 1966, Ref。 36

The investigation encompassed three grades of graphite, ATJ $(p=$ $1.73 \mathrm{~g} / \mathrm{cc}), \operatorname{AHDG}(\rho=1.90 \mathrm{~g} / \mathrm{cc})$ and AGSX $(\rho=1.67 \mathrm{~g} / \mathrm{cc})$; three hemis pherical shaped models, $\mathrm{d}=0.375,0.50$ and 1.0 inches; and three Langley test facilities, the $11^{\prime \prime}$ ceramic-storage-heated tunnel $\left(P_{S}=5.2\right.$ to $\left.7.5 \mathrm{~atm}\right)$, the arc -heated materials jet $(6.4$ to $8.3 \mathrm{~atm})$ and the $20^{\prime \prime}$ hypersonic archeated tunnel $(0.60$ to $0.20 \mathrm{~atm})$. The purpose was to investigate the diffusion-limited oxidation regime. The mass fraction of $\mathrm{O}_{2}$ within the test stream was varied from 0.059 to 0.232 (i.e., air)。

Low contamination for all facilities was claimed by the authors. Mass loss rates were obtained by photographical and post-test measurements of surface recession. Surface temperatures were determined with a photographic pyrometer and ranged from 1600 to $2330^{\circ} \mathrm{K}$. Stagnation heat transfer rates were evidently computed from the Fay and Ridde $11^{3}$ theory although details are not given (e.go, Le number). It is also not clear how the stagnation pressure values were obtained.

The resulting data ( $~ 80$ points), normalized to the co diffusion limit theoretical values, are reproduced in Fig。 8 . The mass loss ratios

*A subsequent version of this reference appeared in the AIAA Journa1 (Ref。35), but did not include a tabulation of the data.

${ }^{* *}$ Maahs ${ }^{37}$ pointed out that the theoretical values employed by Miller and Sutton are $\sim 14 \%$ lower than the diffusion limit of Scala. 
THE JOHNS HOPKINS UNIVERSITY APPLIED PHYSICS LABORATORY SILVER SPRING. MARYLAND

were taken directly from Fig. 13 of Ref. 36. The authors concluded that a diffusion controlled reaction for all three grades of graphite was evident only above $2000^{\circ} \mathrm{K}$. Below $2000^{\circ} \mathrm{K}$, ablation rates were temperature dependent, indicating a transition region between the chemical control and diffusion control oxidation regions. The AHDG and AGSX graphite specimens became highly eroded in the high pressure environments.

5) Maahs, NASA Langley, 1970, Ref。 37

This test series encompassed the following four grades of graph ite: two glass -1 like carbons, LMSC $(\rho=1.41 \mathrm{~g} / \mathrm{cc})$ and Vitreous carbon $(\rho=1.49 \mathrm{~g} / \mathrm{cc})$; a pyrolytic graphite $(\rho=2.15 \mathrm{~g} / \mathrm{cc}) ;$ and an ATJ graphite $(\rho=1.72 \mathrm{~g} / \mathrm{cc})$. Four Langley facilities were utilized, the same three used by Miller and Sutton plus the high-enthalpy arc tunnel. Model stagnation pressures varied from 0.035 to 15 atm and surface temperatures from 1600 to $3450^{\circ} \mathrm{K}$. The test specimens were hemispherical cylinders of $1 / 2^{\prime \prime}$ diameter. Mass loss rates were determined from motion pictures, surface temperatures were measured with a photographic pyrometer, pitot probes were used to record test stream stagnation pressures, and heating rates were measured with a Gardon asymptotic calorimeter. The resulting data are plotted in Fig. 9。 The values of $\dot{m}_{D}$ used to normalize the rates were taken from Maah's Fig. 50 $0^{37}$ He stated that in the high pressure condition $\left(\mathrm{P}_{\mathrm{S}}=\right.$ $15 \mathrm{~atm})$, considerable mechanical erosion was witnessed for the ATJ graphite. He concluded that the measured rates did not confirm the diffusion-limited theoretical predictions of Scala. 


\section{6) Lunde 11 and Dickey, NASA Ames, 1971, Ref. 24}

These tests were conducted to investigate the sublimation region for ATJ graphite $(\rho=1.73 \mathrm{~g} / \mathrm{cc})$. The models were blunted and hemispherically-capped cylindrical specimens in two sizes, $0.60^{\prime \prime}$ and $1.20^{\prime \prime}$ diameter. The tests were conducted in the Ames Heat Transfer Tunnel and encompassed model stagnation pressures from 0.30 to $4.40 \mathrm{~atm}$ and surface temperatures from 2600 to $4033^{\circ} \mathrm{K}$. Stagnation heating rate profiles across the test stream were measured with a water-cooled calorimeter; pressure profiles, with pitot probes; recession rates, with motion pictures; and surface temperatures, with automatic optical pyrometers. The resulting data are plotted in Fig。10, along with two sublimation predictions based on the JANAF thermochemical tabulations. The curve labeled 'JANAF (69)' was discussed in Section II. The 'JANAF (61)' curve is based on JANAF thermochemical data published in 1960-61 for the $\mathrm{C}_{3}$ to $\mathrm{C}_{5}$ carbon species. The $\stackrel{\circ}{\mathrm{m}}_{\mathrm{D}}$ values used to normalize the measured rates were computed from Eq. (27) using the values of pressure and effective nose radius tabulated by lunde 11 and Dickey, ${ }^{24}$ who assumed that the JANAF (61) species were applicable to the sublimation region and regarded the differences between the measured rates and the JANAF (61) predictions as due to mechanical erosion. Mechanical erosion was observed during the test; however, the procedure utilized in quantitatively evaluating erosion appears tenuous as it assumes that a) the JANAF (61) species are correct and b) the blowing relationship utilized by Lundell and Dickey,

$$
\frac{C_{h}}{C_{h_{0}}}=\frac{\ln \left(1.28 B^{\prime}+1\right)}{1.28 B^{\prime}} \text {, }
$$


is applicable. Variations in either the assumed species, thermodynamic data, or blowing relationship could materially alter the 'erosion" estimates. Figure 11 shows $\stackrel{\circ}{\mathrm{m}}_{\mathbf{i}} / \stackrel{\circ}{\mathrm{m}}_{s}$ versus temperature, where $\stackrel{\circ}{i}_{i}$ is the increment between the data point and the $\stackrel{\circ}{\mathrm{m}}_{\mathrm{s}}$ given by the JANAF (69) sublimation curve, as defined in Section $I I$, at the same surface temperature and pressure. The resulting values of $\dot{\mathrm{m}}_{i}$ based on the JANAF (69) thermochemical data are lower than the values reported by Lunde11 and Dickey, with reductions of $50 \%$ occurring at the higher surface temperatures. A curve fit through the bulk of the points, as represented by the solid line, gives

$$
\frac{\stackrel{\circ}{\mathrm{m}}_{\mathrm{o}_{\mathrm{m}}}}{\mathrm{m}_{\mathrm{s}}}=\frac{314}{4178-\mathrm{T}_{\mathrm{W}}}-0.155
$$

which is applicable over the temperature range, $2500^{\circ} \leq \mathrm{T}_{\mathrm{w}} \leq 4050^{\circ} \mathrm{K}$, and stagnation pressure range, $0.3 \leq \mathrm{P}_{\mathrm{S}} \leq 4.40$. As pointed out by Lundell and Dickey, no noticeable effect of pressure on mechanical erosion was evident. However, it should be noted that the values of $\stackrel{\circ}{\mathrm{m}}_{1} / \mathrm{m}_{\mathrm{s}}$ from the reduced data at the higher surface temperatures are based entirely on data measured at the high pressure test condition. It should be emphasized that Eq. (44) is only applicable to the theoretical sublimation curve as defined above and should be viewed as a correction to be applied to the JANAF (69) $\dot{m}_{s}$ curve in order to provide reasonable agreement with the Lunde11 and Dickey data.

C. Summary

This section has presented available experimental data (unclassified) on oxidation and sublimation rates for various graphitic materials 
THE JOHNS HOPKINS UNIVERSITY

APPLIED PHYSICS LABORATORY

SILVER SPRING MARYLAND

(notably, ATJ). Major questions, beyond the validity of the data itself, remain as to the utilization of the information. For instance, the relationship of the laboratory data to arc jet results. The PG predictions based on the laboratory tests and illustrated in Fig. 5 indicate good performance in terms of oxidation resistance characteristics, but there are insufficient data to either support or disprove the results

It appears there is no reliable method of establishing the effect of mechanical erosion for graphites either experimentally or theoretically, as the thermochemical mass loss rates and particulate mass loss rates are strongly coupled. The experimental data of Lundell and Dickey show higher mass losses than the JANAF (69) thermochemical predictions in the sublimation region. The differences are substantial, amounting to $\sim 70 \%$ at $4000^{\circ} \mathrm{K}$. For the current safety analysis of the Pionner F at APL, it is assumed that the differences are due to mechanical erosion; this is a more conservative approach, especially for the extreme superorbital trajectories, than to assume that there is simply a deficiency in the sublimation thermochemical mode1。

An attempt was made to gain some insight on the effect of test facility and experimentalist based on the results of Maahs ${ }^{37}$ and Miller and Sutton. 36 Figure 12 shows experimental rates for ATJ graphite as measured by both studies in three corresponding facilities. The number of data points are sparse and the scatter is large. Agreement among the studies is limited to two points in the AHMJ facility, and disagreement for some points is as great as a factor of $2\left(\mathrm{e} . \mathrm{g}\right.$, at $\mathrm{T}_{\mathrm{s}}=2050-2075^{\circ} \mathrm{K}$ in the HAHT facility)。 
For the current Pioneer $F$ heat source (SNAP-19), the heat shield material is a fine-grain POCO graphite with $\rho \cong 1.80 \mathrm{~g} / \mathrm{cc}$. Mass loss rates for a POCO AXF-5Q grade graphite are reported in Ref. 38; however, the test conditions are more representative of ballistic reentries (i。e, stagnation pressures of 75-100 atm). Consequently, the mass loss data reflect inordinately high percentages of mechanical erosion and are too severe to be applicable to the current reentry configuration with a ballistic coefficient (at $400 \mathrm{Kft}$ ) of $28 \mathrm{lb} / \mathrm{ft}^{2}$, where maximum stagnation pressures are on the order of 10 atm. POCO AXF-5Q ablation results were also reported in Ref。 39; however, the usefulness of the data is limited since surface temperatures were not measured. Here again, stagnation pressures were high (6 to $165 \mathrm{~atm}$ ) with resultingly large percentages of mechanical erosion. This test series encompassed seven materials and six test facilities. It was concluded that "material and testing variables do not permit differentiation in ablation performance among the bulk graphites" and "that five of the six test facilities provided similar results."

\section{Comparison of Theory and Experiment}

Section II reviewed a theoretical graphite ablation model, based essentially on the work of Lees and of Scala and coworkers at G。E。, and Section III presented experimental data on graphite mass loss from the open 1iterature. Figure 13 is a composite graph covering the complete temperature range from the rate-controlled oxidation regime to the sublimation regime. 
This figures includes a) predicted oxidation mass loss profiles based on four sets of reaction rate constants $\left(k_{0}\right.$ and $E$; see $\left.F i g .2\right)$ representing 'fast', 'moderate', 'slow', and 'very slow' reaction rates; b) sublimation predictions based on the Dolton and JANAF (69) thermochemical models with the blowing relationship given by Eq. (33); and c) the experimental data presented in Section III for ATJ graphite. The $\dot{\mathrm{m}} / \dot{\mathrm{m}}_{\mathrm{D}}$ ratios are as presented in Section III recognizing the fact that there are variations in the definition of $\dot{\mathrm{m}}_{\mathrm{D}}$ among the various sets of data. The Lundell and Dickey sublimation data include only that data for the pressure range, $0.9 \leq \mathrm{P}_{\mathrm{S}} \leq$ $1.1 \mathrm{~atm}$. The majority of the data lend support to the 'moderate' oxidation rate, the Scala diffusion limit, and the JANAF sublimation model. However, the data of Maahs ${ }^{37}$ and Miller and sutton $^{36}$ show much lower oxidation rates in the diffusion-limited regime. Theoretical models based on the latter data would lead to substantial reductions in heat shield ablation losses below those indicated by the bulk of the data for most Pioneer $F$ heat source re entries. The oxidation profile labeled 'very slow' represents the optimistic extreme, encompassing all of the data, and was arrived at by arbitrarily reducing $k_{0}$ to $965 \mathrm{lb} /\left(\mathrm{ft}^{2}-\mathrm{sec}\right) \sqrt{\mathrm{atm} / \mathrm{ft}}$ with $\mathrm{E}=44000 \mathrm{cal} / \mathrm{mole}$.

In view of Fig. 13 and considering the conservative approach required in the safety analysis, it is concluded that the Scala diffusion limit, the 'moderate' rates and the JANAF (69) species along with Eq. (44) should be utilized as the nominal case for purposes of estimating ablation 1osses. Variations about the above model to encompass the majority of the data are; a) in the transition regime a variation of $10 \pm 1 k_{0}, p l u s$ and minus an order of magnitude of the moderate reaction rate constant, $k_{0}, b$ ) in the 
THE JOHNS HOPKINS UNIVERSITY APPLIED PHYSICS LABORATORY

SILVER SPRING. MARYLAND

diffusion regime, $+10 \%$ to $-50 \%$ of $\dot{\mathrm{m}}_{\mathrm{D}}$ and $\mathrm{c}$ ) in the sublimation regime $\pm 20 \%$ of $\stackrel{\circ}{\mathrm{m}}$

The POCO graphite (currently favored heat shield material) has a higher density $(\sim 6 \%)$ than ATJ, and it is generally accepted that the oxidation resistance is proportional to density since the porosity is $\propto 1 / \rho$. This trend has been verified when comparing PG and a low density graphite, 28 however, in an experimental study directed toward determining the relationship between oxidation behavior and density ${ }^{40}$ it was concluded that for the four graphites tested ( $\rho=1.55$ to $2.08 \mathrm{~g} / \mathrm{cc}$, temperatures from 1500 to $2300^{\circ} \mathrm{K}$ ) there was no relationship between the rate of reaction and the density. Consideration of the above results, the absence of experimental data for POCO and the scatter in the ATJ data about the 'moderate' curve it appears that there is no justification for a reduction in the 'moderate' ablation rates for the POCO grade graphite.

Thermal studies of the Pioneer-F heat source, on various trajectories, utilizing the models documented herein will be reported in a forthcoming memorandum. 
1. "SNAP 19/Pioneer F Safety Analysis Report, Vol. IV, Accident Response," INSD-2873-42-2, Teledyne Isotopes, Timonium, Md., June 1971 .

2. Scala, S. M. and Gilbert, L。 M。, "Aerothermochemical Behavior of Graphite at Elevated Temperatures," G.E. Report 非63SD89, General E lectric, Missile and Space Division, Nov。1963.

3. Fay, J。A. and Ridde11, F. R., "Theory of Stagnation Point Heat Transfer in Dissociated Air," 吕, Vo1。25, No.2, pp. 54-67, Feb. 1958.

4. Scala, S. M., "The Ablation of Graphite in Dissociated Air 1. Theory," G。E. Report 非62SD72, General Electric, Missile and Space Division, Sept。1962.

5. Lees, L。, "Laminar Heat Transfer Over Blunt-Nosed Bodies at Hypersonic F1ight Speeds," Jet Propulsion, Vo1. 26, No. 4, pp. 259-269, Apri1 1956.

6. Lees, L。, "Convective Heat Transfer with Mass Addition and Chemica1 Reaction," Pub。 in Combustion and Propulsion, 3rd AGARD Colloquium, March 17-21, 1958, Pergamon Press, N. Y。, 1958.

7. Knuth, E. L., "Multicomponent Diffusion and Ficks Law," Phys. Fluids, Vo1。2, pp。339-340, 1959 .

8. Maahs, H.G., "Oxidation of Carbon at High Temperatures: Reaction-Rate Control or Transport Contro1," NASA TND-6310, June 1971.

9. Binford, Jr., J. S., "Kinetics of the Oxidation of Graphite," Pub. in Advances in Chemistry Series, Vol. 20, American Chem. Society, Wash., D。C。, Pp. 39-48, Feb. 1958 . 
THE JOHNS HOPKINS UNIVERSITY APPLIED PHYSICS LABORATORY

SILVER SPRING. MARYLAND

10. Walker, Jr., P. L., Rusinko, Jr., F. and Austin, L. G., "Gas Reactions of Carbon," Pub. in Advances in Catalysis and Related Subjects, Vo1. XI, Ed.E1ey, D。D., et a1., Academic Press, Inc., N. Y., pp. 133-221, 1959.

11. Metzger, J. W. Enge1, M. J. and Diaconis, N. S., "The Oxidation and Sublimation of Graphite in Simulated Re-entry Environments," AIAA Preprint Paper No. 65-643, 1965.

12. Frank-Kamenetskii, D. A., Diffusion and Heat Transfer in Chemica1 Kinetics, 2nd Ed., Plenum Press, N. Y., 1969.

13. Welsh, Jr。, W. E. and Chung, P. M., "A Modified Theory for the Effect of Surface Temperature on the Combustion Rate of Carbon Surfaces in Air," Proceedings of 1963 Heat Transfer and Fluid Mechanics Institute, Stanford Press, Ca1if。, pp.146-159, 1963.

14. Scala, S. M. and Gilbert, L. M., "Sublimation of Graphite at Hypersonic Speeds," AIAA Journa1, Vo1. 3, No. 9, pp. 1635-1644, Sept. 1965.

15. "User"s Manua1. Aerotherm Charring Material Therma1 Response and Ablation Program, Version 3," Vo1. I and Vo1. II, Aerotherm Report No. UM-70-14, Apri1 1970。

16. Mickley, H. S., Ross, R. C., Squyers, A. L. and Stewart, W. E., "Heat, Mass, and Momentum Transfer for Flow over a Flat P late with Blowing or Suction," NACA TN-3208, July 1954.

17. Simon, H. A., Hartnett, J. P. and Liu, C. S., "Transpiration Cooling Correlations for Air and Non-Air Free Streams," Pub. in Progress in Heat and Mass Transfer, Vo1。2, Ed. Irvine, T.F., et a 1., Pergamon Press, N. Y。, pp. 187-194, 1969. 
18. Dow Chemica1 Co., "JANAF Thermochemica1 Tables," Midland, Mich., June 1971 ,

19. "User's Manua1, Aerotherm Equilibrium Thermochemistry Computer Program, Version 3," Vo1. I and Vo1. II, Aerotherm Report No. UM-70-13, April 1970 。

20. Dolton, T. A., Mauerer, R. E., and Goldstein, H. E., "Thermodynamic Performance of Carbon in Hyperthermal Environments," AIAA Preprint Paper No. 68-754, June 1968.

21. Kratsch, K.M., Martinez, M. R., Clayton, F. I., Greene, R. B. and Wuerer, J. E., "Graphite Ablation in High-Pressure Environments," AIAA Preprint Paper No. 68-1153,

22. Rinda1, R. A. and Powars, C. A., "Effects of Carbon Vapor Thermochemistry Uncertainties on R/V Ablation Predictions," AIAA Preprint Paper No. 71-414, April 1971.

23. Personal communication. Letter from Powars, C., Aerotherm Corp. to Weiss, R。, Applied Physics Lab., dated July 28, 1971.

24. Lunde11, J.H. and Dickey, R. R., "Graphite Ablation at High Temperatures," AIAA Preprint Paper No. 71-418, Apri1 1971.

25. Riley, W。C., "Graphite," Pub. in High-Temperature Materials and Technology, by Campbe11 and Sherwood, John Wiley and Sons, Inc。, N.Y., pp. 188-234, 1967 . 
26. Horton, W. S., "Oxidation Kinetics of Pyrolytic Graphite," Pub. in Conference on Carbon, 5th Proceedings, Vol. 2, pp. 233-241, 1963.

27. Nagle, J. and Strickland-Constable, R. F。, "Oxidation of Carbon Between 1000-2000 $\mathrm{C}, "$ Pub. in Conference on Carbon, Proceedings of the Fifth (5th), Vo1。1, pp. $154-164,1962$

28. Wa11s, J.R. and Strickland-Constable, R. F., "Oxidation of Carbon Between $1000-2400^{\circ} \mathrm{C}, "$ Pub. in Carbon, Vol。1, Pergamon Press Ltd., pp. $333-338,1964$.

29. Schiff, D., "Pyrolytic Materials for Reentry Application," Metals Engineering Quarter1y, Vo1. 2, No. 4, pp. 32-42, Nov. 1962.

30. Levy, M. and Wong, P., "The Oxidation of Pyrolytic Graphite at Various Temperatures and Air Velocities," AMRA TR 65-18, U. S.Army Materials Research Agency, Watertown, Mass., July 1965.

31. Levy, M。, "Oxidation of Pyrolytic Graphite in Air Between $1250^{\circ}$ and $1850^{\circ} \mathrm{F}, " \mathrm{I} . \& \mathrm{E} . \mathrm{C}$. Product Research and Development, Vo1. 1, No. 1, pp. 19-23, March 1962 .

32. Golovina, E。 S. and Khaustovich, G. P., "The Interaction of Carbon with Carbon Dioxide and Oxygen at Temperatures Up to $3000^{\circ} \mathrm{K}$, Pub。 in Eighth Symposium (Internationa1) on Combustion, Williams and Wilkins, pp.784792,1962 .

33. Essenhigh, R。H., "Discussion by R. H. Eisenhigh," Pub. in Eighth Symposium (Internationa 1) on Combustion, Williams and Wilkins, pp. $813-814,1962$ 
34. Diaconis, N. S., Gorsuch, P. D. and Sheridan, R. A., "The Ablation of Graphite in Dissociated Air - Experimental Investigation," G. E. Report 非62SD86, Genera1 Electric, Missile and Space Division, Sept. 1962 .

35. Metzger, J.W., Enge1, M. J. and Diaconis, N. S., "Oxidation and Sublimation of Graphite in Simulated Re-Entry Environments," AIAA Journa1 Vo1。5, No. 3, pp. 451-460, March 1967.

36. Miller, I。 M。 and Sutton, Ko, "An Experimental Study of the Oxidation of Graphite in High-Temperature Supersonic and Hypersonic Environments," NASA TN D-3444, July 1966 。

37. Maahs, H。G., "Ablation Performance of Glasslike Carbons, Pyrolytic Graphite, and Artificial Graphite in the Stagnation Pressure Range 0.035 to 15 Atmospheres," NASA TN D-7005, Dec. 1970 .

38. Grabowsky, W. R. and Strickler, R. L., "High Quality Ablation Experimental Resu1ts, Phase I," Aerospace Report No. TR-0066 (S5816-74)-2, The Aerospace Corp., San Bernardino, Calif., Apri1 10, 1970.

39. Auerbach, I。, Bader, B.E., McBride, D.D., and McVey, D。F。, "Recent Graphite Nosetip Developments," AIAA Preprint Paper No. 71-417, Apri1 1971 。

40. Yavorskiy, I.A. and Malanov, M. D., "Special Features of the Interaction of Graphitized Carbon Materials with Gases in the 700-2500 ${ }^{\circ}$ Temperature Region," Khimiya Tverdogo Topliva, No. 1, 1969, pp. 139-144, Translation FTD-HT-23-631-69, available from Clearinghouse, Springfield, Va., AD 706182. 


\section{NOMENCLATURE}

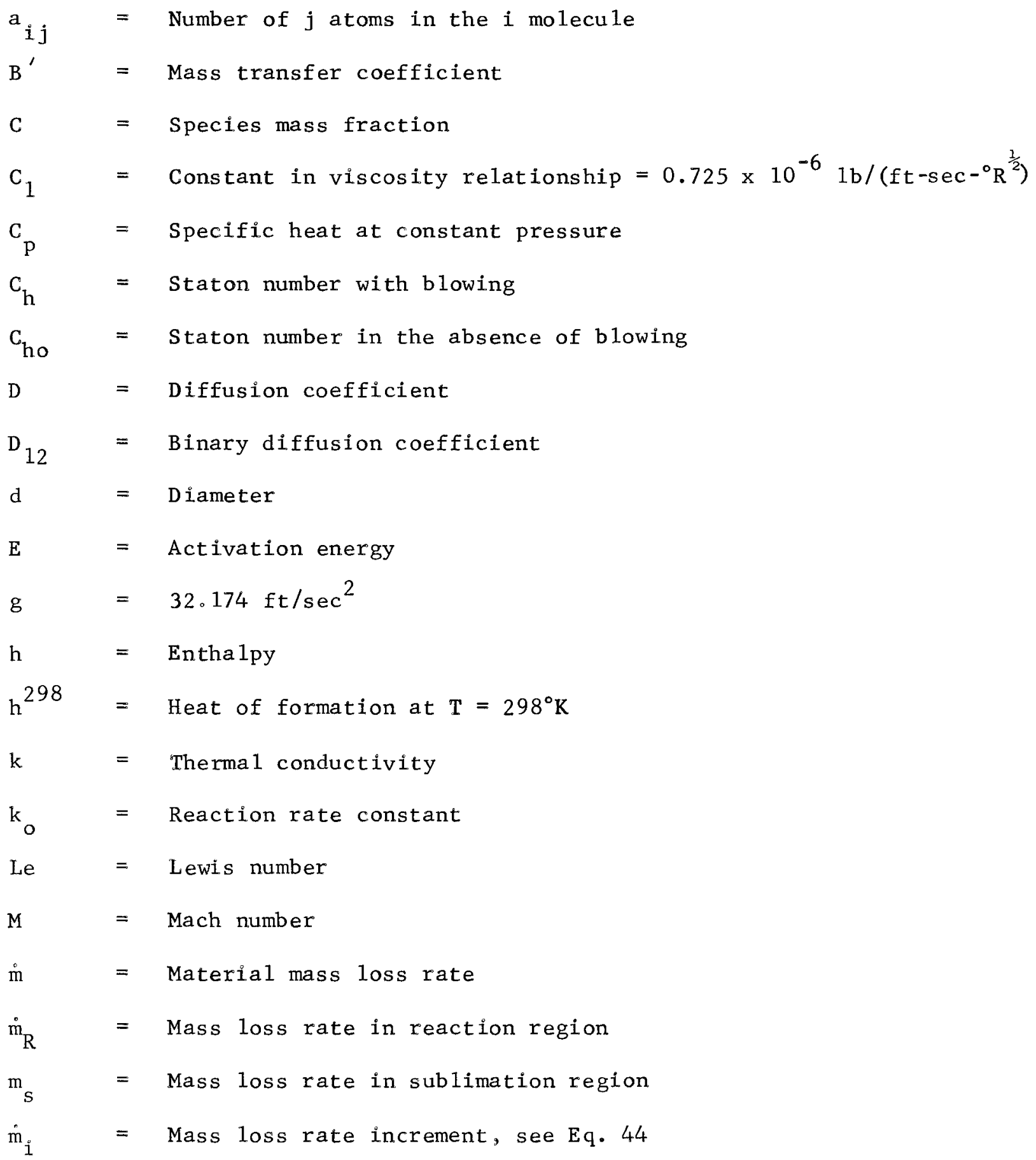




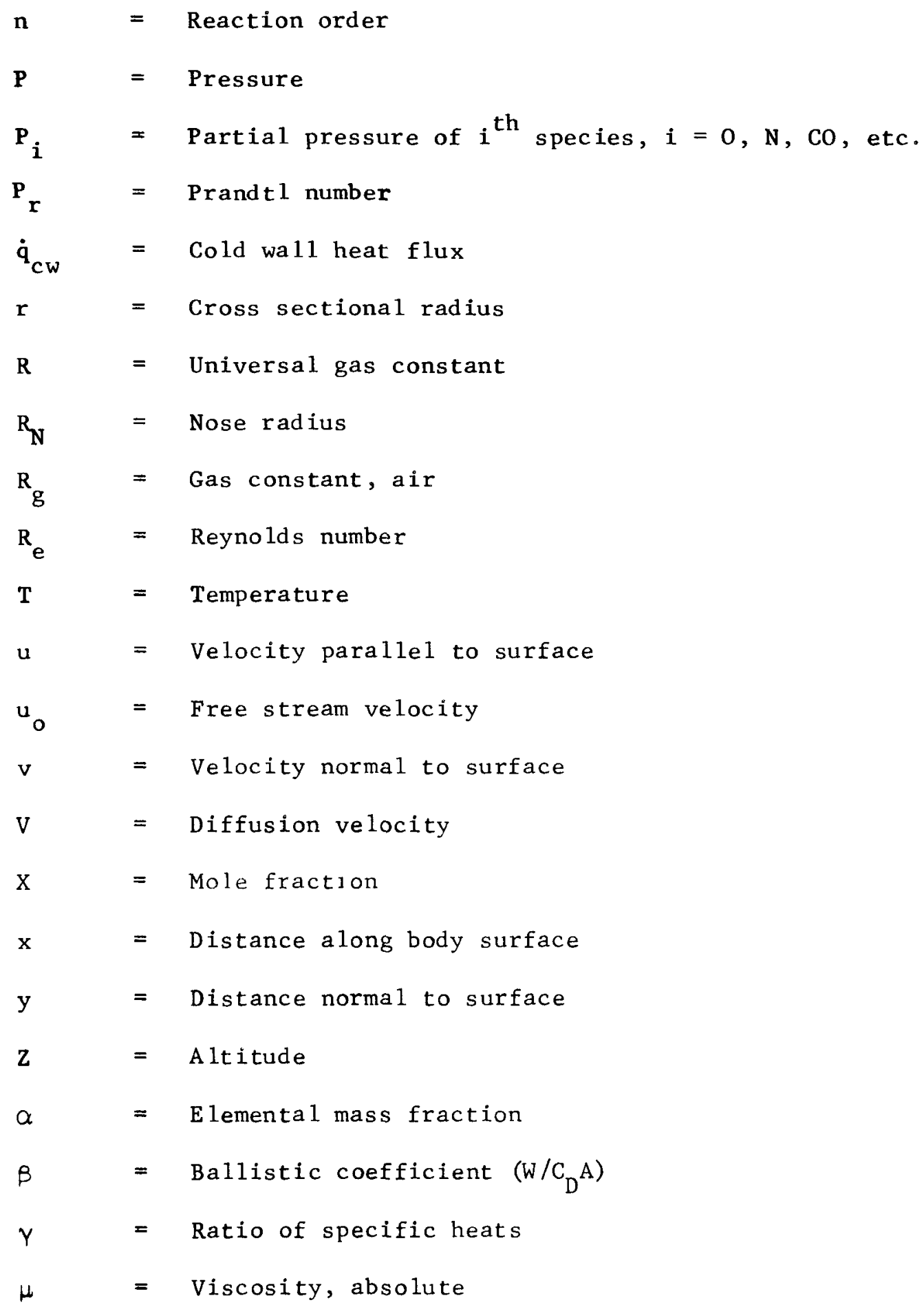


THE JOHNS HOPKINS UNIVERSITY

APPLIED PHYSICS LABORATORY

SILVER SPRING. MARYLAND

$\begin{aligned} \rho & =\text { Density } \\ \omega & =\text { Species production rate } \\ m & =\text { Molecular weight } \\ \sim & =\text { Approximately }\end{aligned}$

Subscripts

$=$ Diffusion region

e $=$ Edge of boundary layer

g = Gaseous phase

i $=$ Chemical species

j $=$ Chemical elements

s = Stagnation point, solid phase

$t=$ Tota 1 conditions

$\mathrm{W}=\mathrm{Wa} 11$ 
Table I Pyrolytic Graphite Test Conditions for Data in Fig. 4

\begin{tabular}{|c|c|c|c|c|c|c|c|c|}
\hline Symbo1 & Ref. & Gas & $\underline{P(A T M)}$ & $\Delta \mathrm{T}_{2}{ }^{\circ} \mathrm{K}$ & $\underline{u_{2} F P S}$ & $\rho g / c c$ & Heating $^{a}$ & Specimen \\
\hline+ & 31 & Air & 1 & $950-1030$ & 0 & 2.20 & $\mathrm{~F}$ & $0.37 \times 0.37 \times 0.13^{\prime \prime}$ \\
\hline$\sigma$ & 30 & Air & 1 & $1035-1255$ & 0.8 & 2.20 & $F$ & $0.37 \times 0.37 \times 0.13^{\prime \prime}$ \\
\hline 口 & 30 & Air & 1 & $1035-1255$ & 1.6 & 2.20 & $F$ & $0.37 \times 0.37 \times 0.13^{\prime \prime}$ \\
\hline 口 & 30 & Air & 1 & $1035-1255$ & 2.5 & 2.20 & F & $0.37 \times 0.37 \times 0.13^{\prime \prime}$ \\
\hline b & 30 & Air & 1 & $1035-1255$ & 3.3 & 2.20 & $\mathrm{~F}$ & $0.37 \times 0.37 \times 0.13^{\prime \prime}$ \\
\hline$\triangle$ & 26 & Air, $\mathrm{O}_{2}$ & 1 & $890-1840$ & $0.5 \rightarrow 1.0$ & 2.15 & $\mathrm{~F}$ & Discs, $\mathrm{d}=2 \mathrm{~cm}, \mathrm{t}=0.5 \rightarrow 2 \mathrm{~mm}$ \\
\hline 0 & 27 & $\mathrm{O}_{2}$ & .23 & $1275-2275$ & 230 & 2.19 & $\mathrm{E}$ & Rod, $4 \mathrm{~mm} \times 2 \mathrm{~mm}$ \\
\hline$\circ$ & 27 & $\mathrm{O}_{2}$ & .20 & $1275-2275$ & 36 & 2.19 & $\mathbf{E}$ & $\operatorname{Rod}, 4 \mathrm{~mm} \times 2 \mathrm{~mm}$ \\
\hline D & 28 & $\mathrm{O}_{2}$ & .21 & $1275-2675$ & 230 & 2.19 & $E$ & $\operatorname{Rod}, 4 \mathrm{~mm} \times 2 \mathrm{~mm}$ \\
\hline 0 & 28 & $\mathrm{O}_{2}$ & .21 & $1275-2675$ & $>82$ & 2.20 & $\mathrm{E}$ & Rod, $4 \mathrm{~mm} \times 2 \mathrm{~mm}$ \\
\hline region & 29 & Air & 1 & $1475-2555$ & $?$ & $?$ & $?$ & $?$ \\
\hline
\end{tabular}

$a_{E}=$ electrically heated specimen; used a jet of unheated $o_{2}$ impinging norma 1 to the rod axis.

$F=$ furnance. 


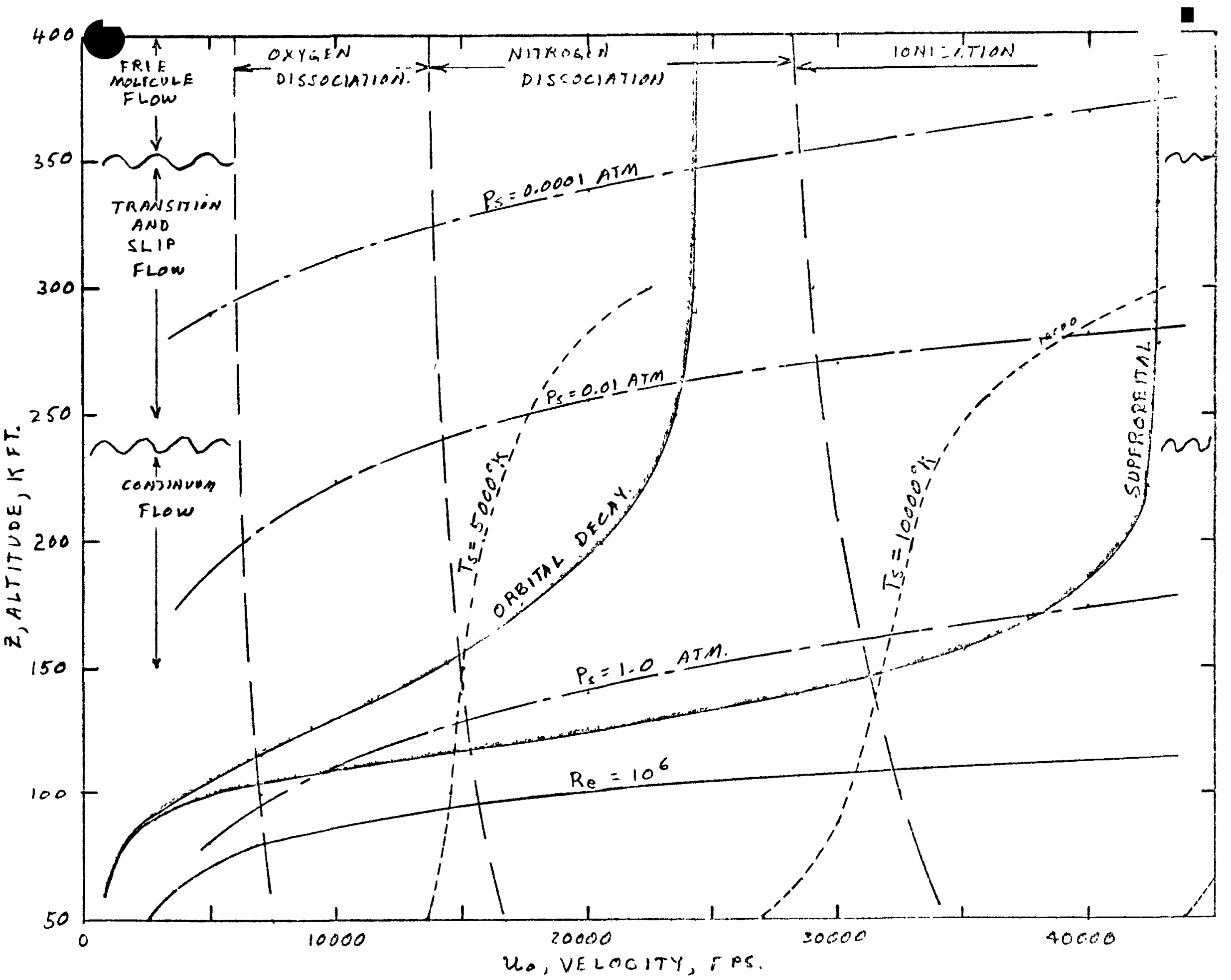

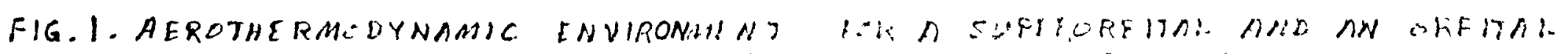

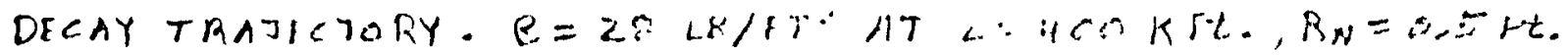




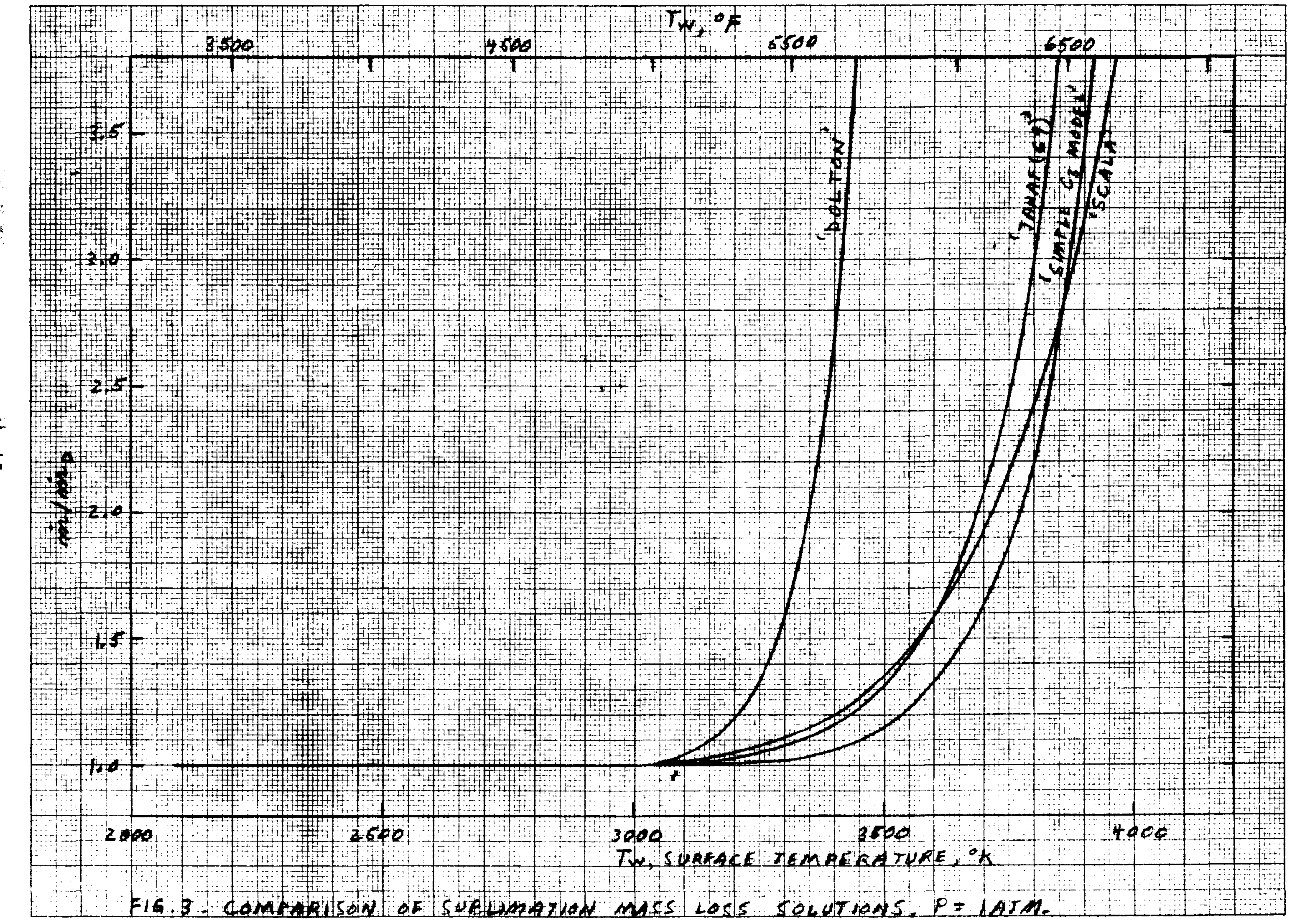




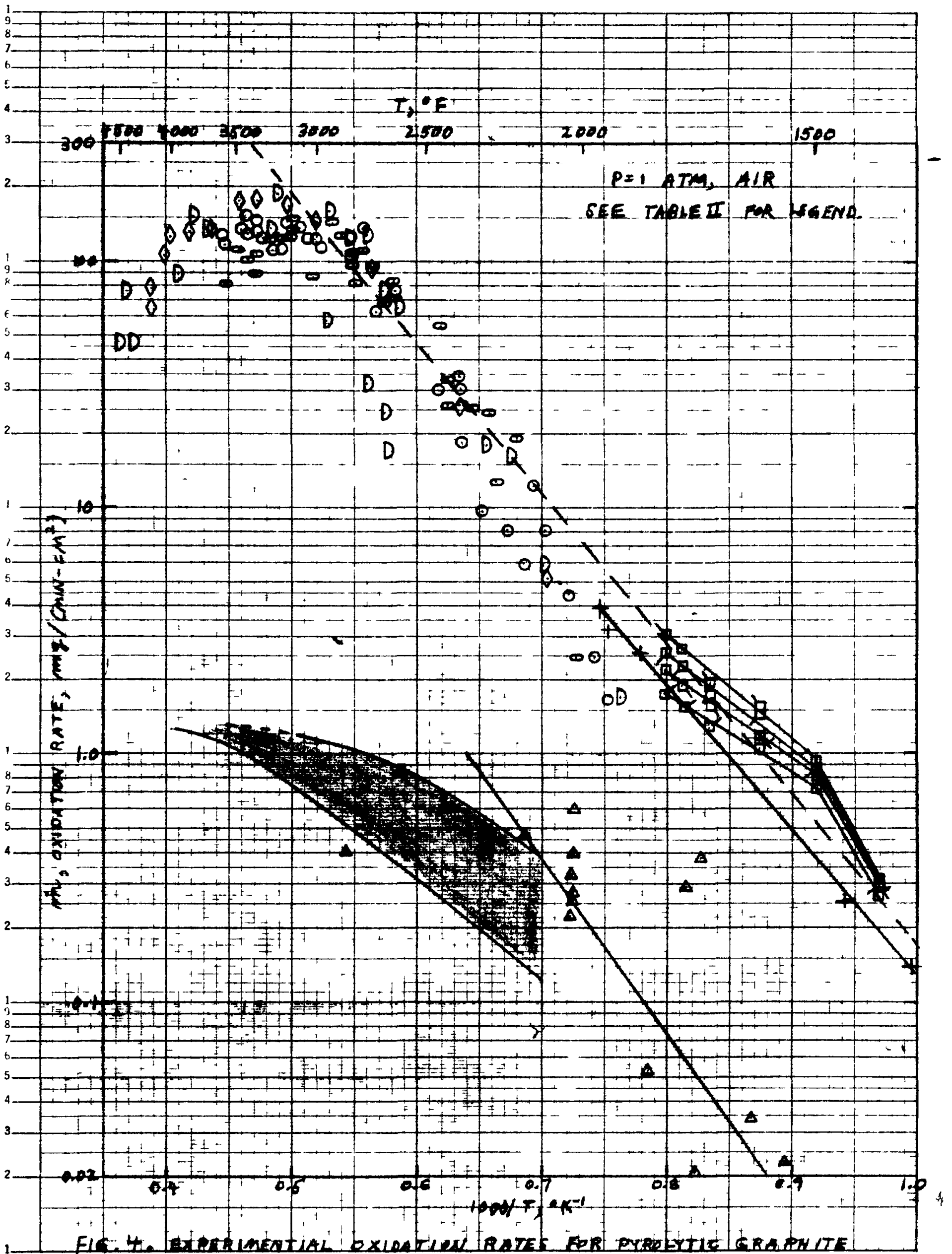


1.4

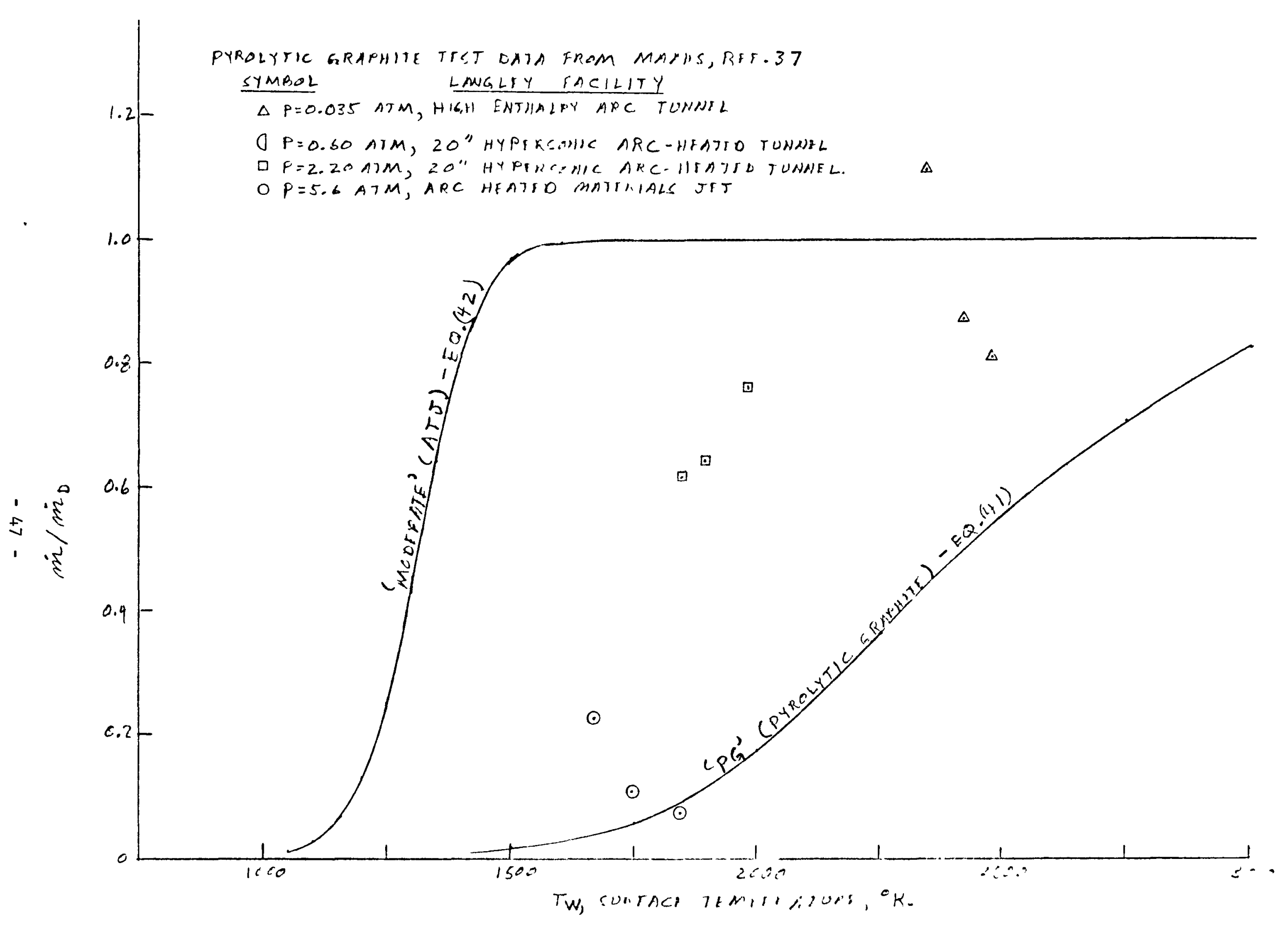

FIG. 5. PYROLYTIC GRAPHITE TRANSITIAN RIGIOH MASS DES RATRE. 


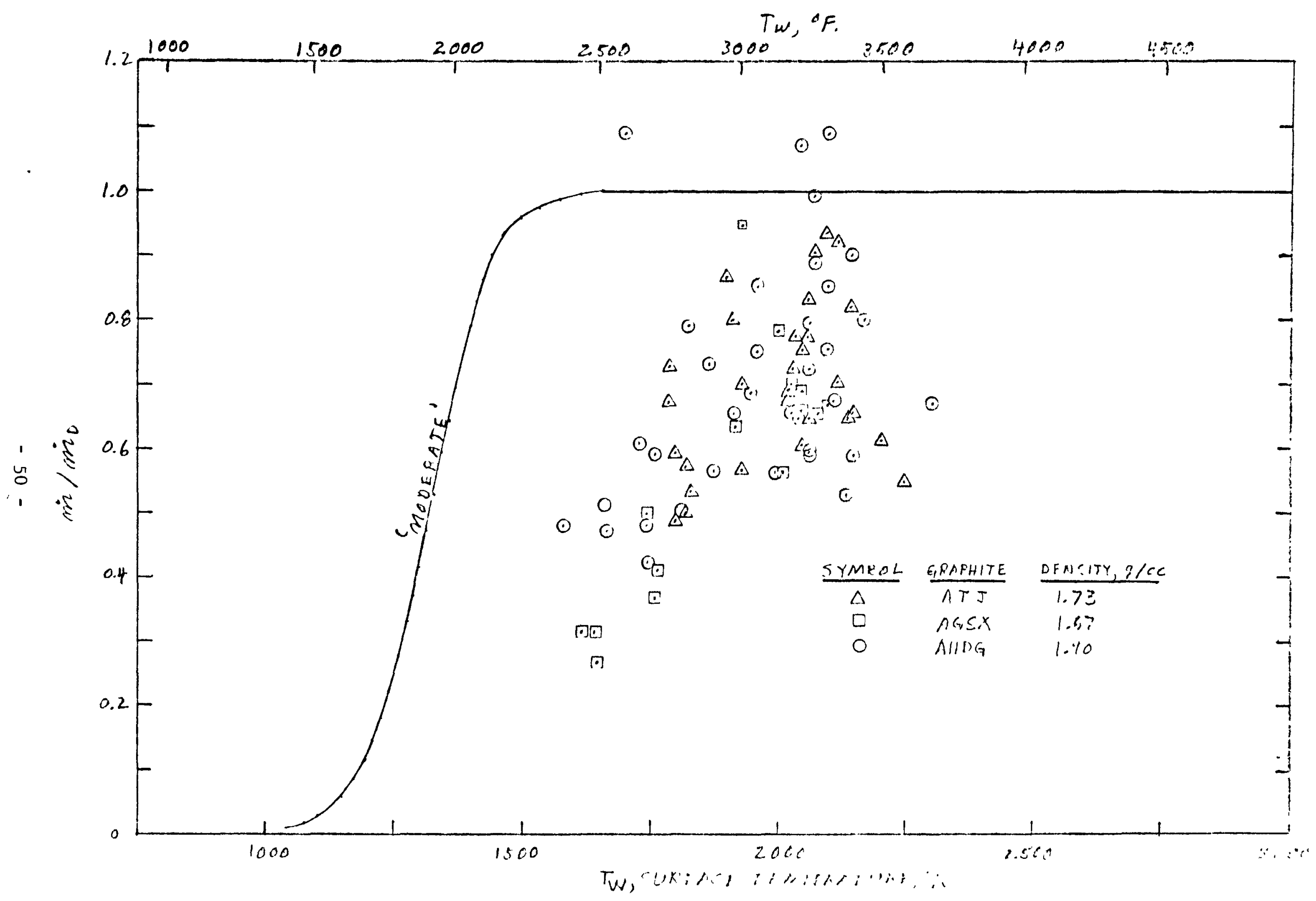

FIG.8. EXPERIMLNTAL ARLATHOH KATES. MILLE: AND SUTTIN" 


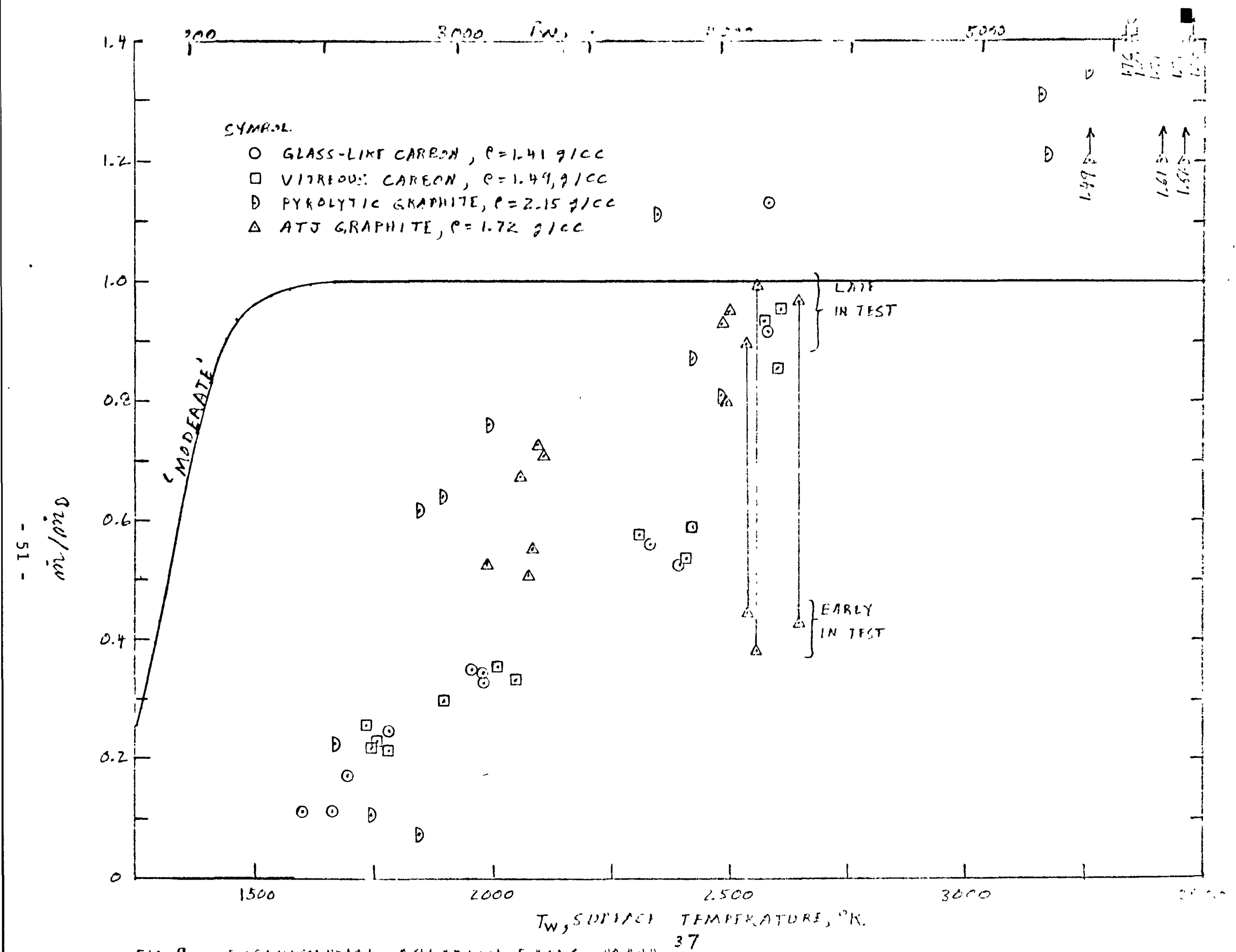

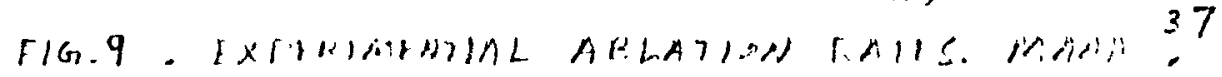




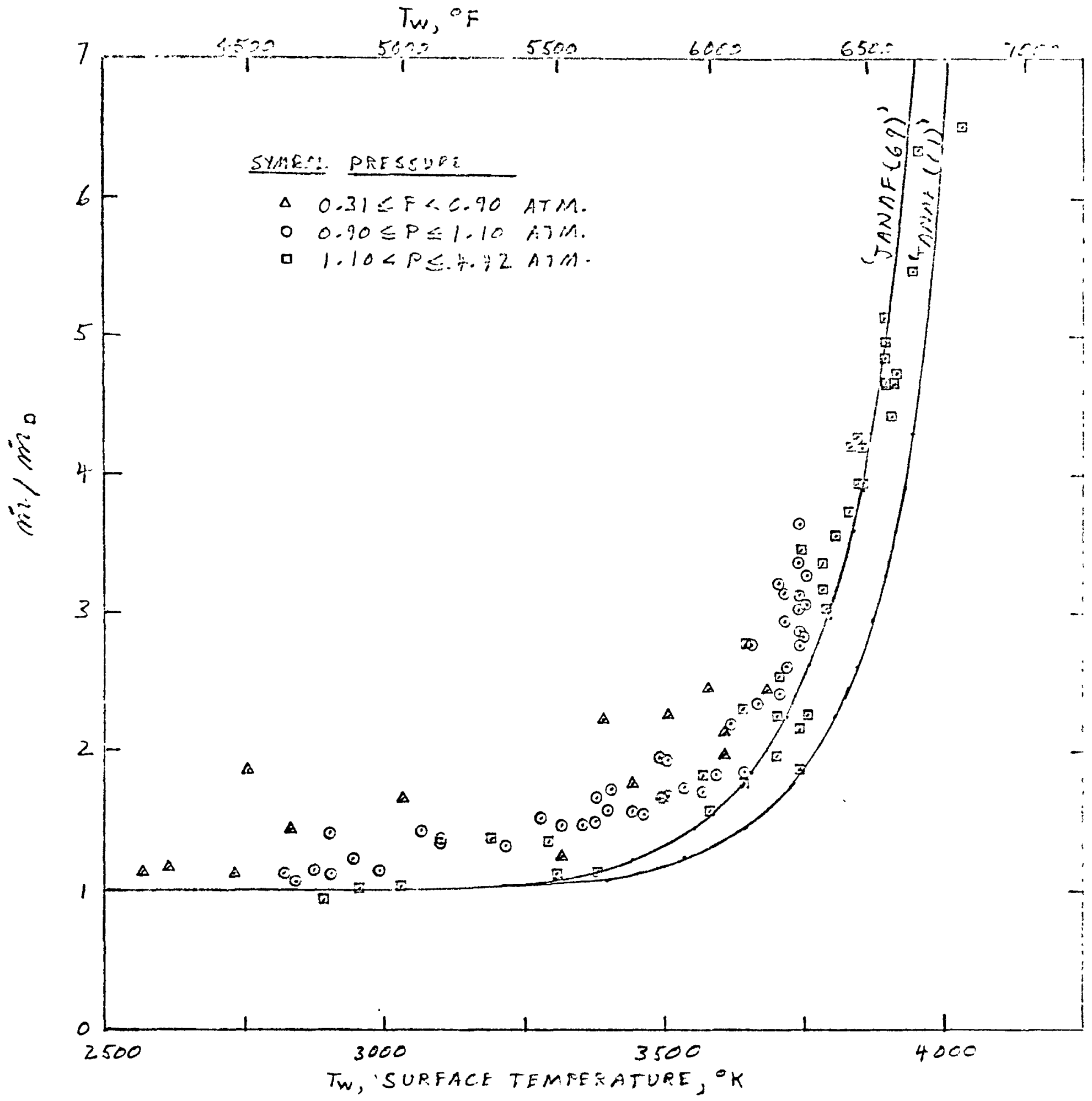

FIG. 10 EXFEFIMENTIAL SUELIOATISA RATES, LUNDELL AMD

$$
\text { DICKEY? }
$$

JANAF CURVES FOR $P=1$ ATIA

$-52-$ 


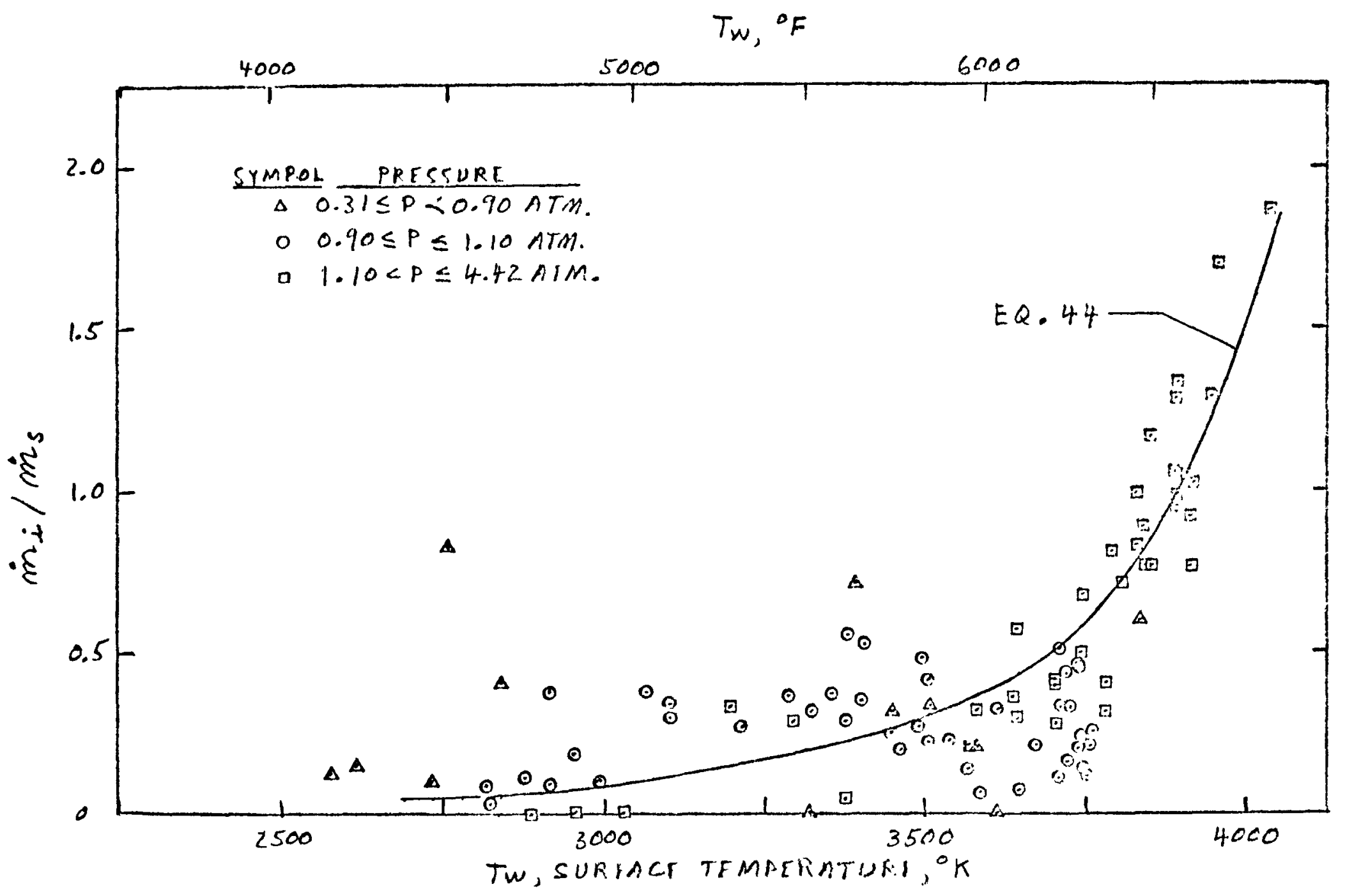

FIG.11. INCREMINTAL. MASS LOSS KATL ( Mij) MROVI JANAT (G9) RATIS. 


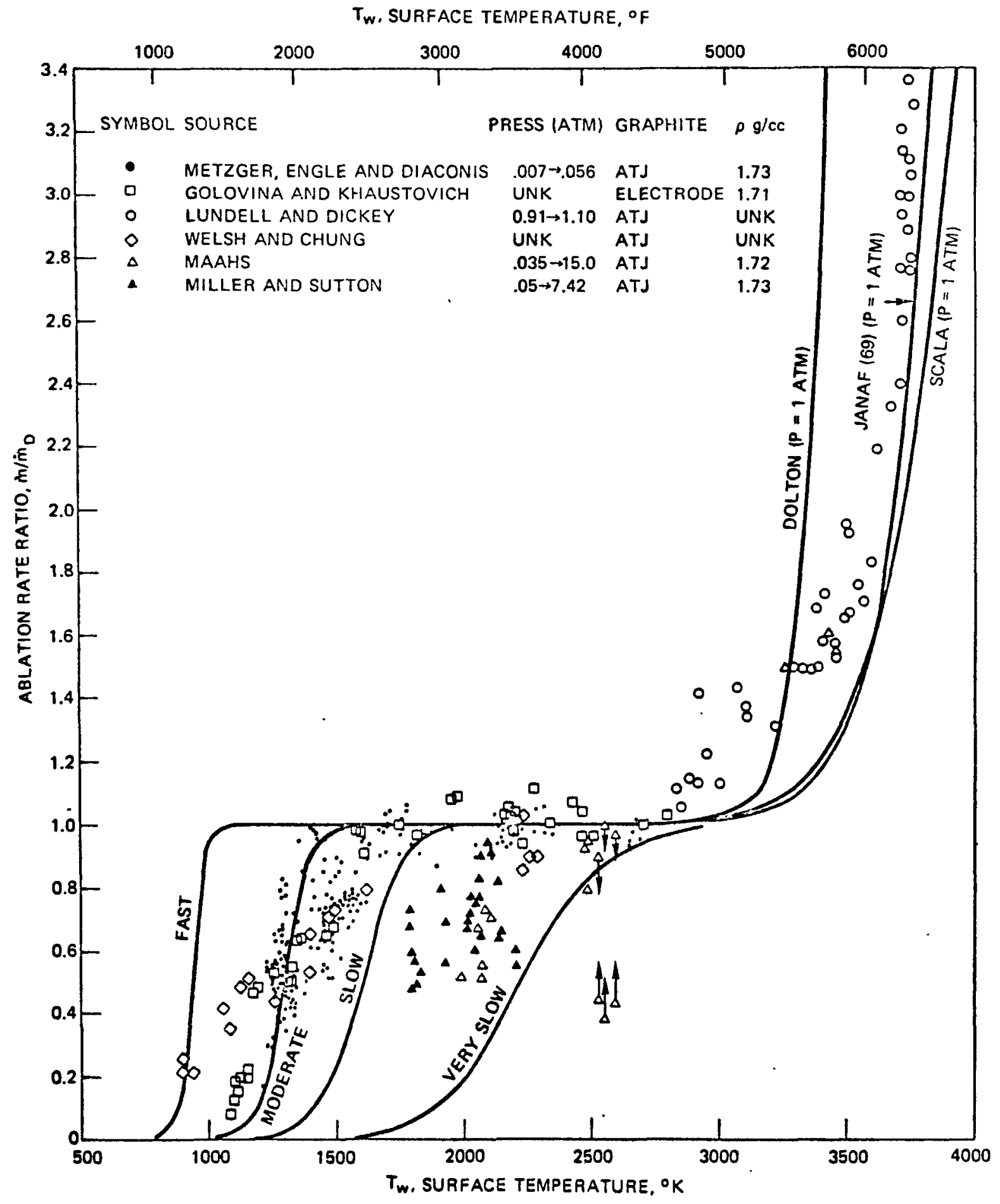

Fig. 13 Comparison of theoretical models and experimental data for axisymetric bodies. 